\title{
Enhanced Information Disclosure and Drug Development: Evidence from Mandatory Reporting of Clinical Trials
}

\author{
Po-Hsuan Hsu, Kyungran Lee, S. Katie Moon, and Seungjoon Oh*
}

April 25, 2020

\begin{abstract}
Using Section 801 of the Food and Drug Administration Amendments Act of 2007 (FDAAA) that requires drug developers to disclose clinical trial plans and detailed study results publicly, we provide novel evidence for the effect of information disclosure on drug development. We find suspensions increase significantly in industry-sponsored clinical trials after the FDAAA. This effect has a causal interpretation based on a difference-in-differences analysis that exploits the disclosure requirement imposed by the International Committee of Medical Journal Editors (ICMJE) before the FDAAA. Further evidence supports peer learning as a mechanism for the increased suspensions after the FDAAA. Finally, we analyze the social welfare implications of enhanced information disclosure; while the FDAAA helps improve drug quality, it leads to more suspensions of potential new drugs that could have reduced mortality and morbidity.
\end{abstract}

Keywords: Mandatory Information Disclosure, Information Diffusion, Divestment, Welfare Analysis

JEL Classification: I18, G30, D80, O32

\footnotetext{
*Hsu is from the College of Technology Management, National Tsing Hua University (pohsuanhsu@mx.nthu.edu.tw), Lee is from the Faculty of Business and Economics at the University of Hong Kong (kyunglee@,hku.hk), Moon is from the University of Colorado (katie.moon@colorado.edu), and Oh is from the HSBC Business School, Peking University (sjoonoh@phbs.pku.edu.cn). We thank Philip Bond, Yao-Ming Chiang, Ran Duchin, Lora Dimitrova, Liran Einav, Luminita Enache, Jarrad Harford, Christopher Hrdlicka, Christopher Parsons, Ivan Png, Lea Stern, Yanzhi Wang, Alminas Zaldokas, participants of the 2019 Hong Kong Junior Accounting Faculty Conference, the 2019 Northern Finance Association meetings, the NTU-NTHU Symposium on Innovation Economics and Entrepreneurship, and 2020 Financial Accounting and Reporting (FARS) Section Midyear Meeting, and seminar participants at National Taiwan University, Peking University HSBC Business School, Korea University, KAIST, the University of Colorado Boulder, and University of Washington - Seattle. All errors are our own.
} 


\section{Introduction}

The disclosure of a firm's progress with respect to innovative activities is often detrimental to its value due to potential imitation and subsequent learning that its competitors obtain (Arrow, 1972; Horstmann et al., 1985; Levin et al., 1987; Cohen et al., 2000; Anton and Yao, 2004). However, governments may promote and adopt policies (e.g., patent systems) to incentivize and mandate the disclosure of innovation for social welfare due to the public-good nature of innovation. ${ }^{1}$ On the other hand, when firms must disclose their innovative activities, they reduce their investment due to the loss of proprietary knowledge and rents (Scotchmer and Green, 1990; Anton and Yao, 1994). ${ }^{2}$ Although the patent system has been well studied in terms of its consequences with respect to disclosure effects (e.g., Williams, 2017), little is known about the impacts of mandatory disclosure of new drugs' clinical trial outcomes (both successful and unsuccessful). We aim to examine those impacts in this study.

The development of new drugs is one of the most costly innovative activities in many dimensions: it involves significant research investment, long hours of laboratory experiments, a large number of animal lives, and many human subjects. Thus, pharmaceutical firms have strong incentives to not publicly disclose the details of clinical trials because of the associated proprietary costs. In the past, these firms only needed to file their clinical trial plans and data to the U.S. Food and Drug Administration (FDA) for regulation and approval. In this past circumstance, only limited information on initiations and terminations of projects was available, not the study details such as treatment and experimental designs.

Nevertheless, the development of new drugs greatly serves the public's interest. Hence, timely and accurate information about the details of clinical trials is important, because it facilitates scientific knowledge accumulation and discovery processes and advocates patient rights, all of which seek to enhance public health (Lehman and Loder, 2012). Thus, public interest has imposed great pressure on the government and administrative bureaus (FDA and NIH) regarding

\footnotetext{
${ }^{1}$ The patent system exemplifies such an intervention by encouraging individuals or organizations to share their inventions with the public in exchange for exclusive usage rights of their inventions for a certain period (e.g., Judd, 1985; Arora, 1995; Arora et al., 1998; Merges, 2005; Hellmann, 2007; Elfenbein, 2007).

${ }^{2}$ The literature has highlighted the necessity and associated costs for entrepreneurs when they disclose their innovations to raise external funding and to mitigate information asymmetries (Leland and Pyle, 1977; Bhattacharya and Ritter, 1983, Ferreira et al., 2014). On the other hand, some studies discuss firms' voluntary disclosure of their patenting activities for strategic reasons (Anton and Yao, 2004; Guo et al., 2004; Gill, 2008; James, 2011).
} 
information disclosure. ${ }^{3}$ As a response to this pressure, Congress enacted the Food and Drug Administration Amendments Act (FDAAA) in 2007, in which Section 801 heightened information disclosure requirements with respect to new drug development (we offer more detail in Appendix A). This Act basically mandates the disclosure of the designs and outcomes of clinical trials, and the literature confirms substantially enhanced disclosure afterward (Gill, 2012; dos Santos and Atallah, 2015). We use this enactment of the FDAAA in 2007 as a quasi-natural shock for identification to examine the causal effect of enhanced information disclosure on firm investments in drug development.

We argue that the FDAAA changed information environments for drug developers and the general public by mandating the disclosure of the details of clinical trials. While, during the preFDAAA period, some drug developers might have some information on the progress of all relevant ongoing projects in the market, they did not have comprehensive information about the clinical designs and outcomes of those projects. Importantly, we note that the changes in information environments are more likely to be concerned with unsuccessful outcomes of clinical trials because successful outcomes could be effectively released by voluntary disclosures before the FDAAA.

We use the BioMedTracker (BMT) database that covers progresses of a broad scope of drug projects (i.e., clinical trials) based on multiple sources of information such as ClinicalTrial.gov, press releases, company websites, earning conference calls, and especially expert industry analysts who closely monitor companies, clinical trials, deals, and regulatory meetings to capture and report on the most critical events. In particular, we focus on industry-sponsored clinical trials for new drugs ("projects") that were initiated between 2002 and 2012 as a ten-year event window around the FDAAA in $2007 .^{4}$

We first examine whether such mandatory disclosure leads to lower investment by drug developers, as predicted in the prior economics literature. We use the suspension of a project to proxy for divestment. We find that the project suspension likelihood increases by $12.6 \%$ following

\footnotetext{
${ }^{3}$ Patient advocacy groups had long lobbied for access to up-to-date information about potentially life-saving therapies (Gill, 2012). Industry associations and international policies all urge more disclosure of clinical trials (Tse and Zarin, 2009; Zarin et al., 2016; Lassman et al., 2017).

${ }^{4}$ Non-industry-sponsored (henceforth, academic or academic-sponsored) clinical trials are projects with principal investigators from non-profit organizations such as universities and hospitals supported by federal (NIH), states, and non-profit foundations. Academic-sponsored clinical trials may have different incentives and funding constraints and thus we limit our sample to industry-sponsored clinical trials.
} 
the enactment of the FDAAA. We control for many factors that may affect suspension decisions, ${ }^{5}$ as well as fixed effects for firms, clinical trial phases, and project indications (i.e., the target disease, illness, or symptom to be treated). As a robustness check, we also find that the number of project initiations decreases by $18.4 \%$ after the enactment of the FDAAA.

To strengthen a causal interpretation of the result, we exploit a difference in compliance timing with mandatory disclosure requirements between industry-sponsored vs. academic-sponsored clinical trials. About three years before the FDAAA was enacted, the joint editorial of the International Committee of Medical Journal Editors (ICMJE) was introduced in September 2004. The ICMJE is a new policy published by several important medical journals that requires submitters to register their projects in a comprehensive and publicly available database before their submissions (De Angelis et al., 2004, 2005). Given academics' incentive to publish papers based on clinical trials (regardless the outcomes being successful or failed), we expect the majority of academic-sponsored projects have been disclosed under the ICMJE policy. Under this policy, a company developing a project in an indication with many academic-sponsored projects would have received more information before the FDAAA than another developing a project in an indication with few academic-sponsored projects. As a result, the amount of information disclosed by academic-sponsored projects would have not changed as much as that by industry-sponsored projects in compliance with the FDAAA for the first time.

Exploiting the timing difference between the ICMJE policy and the FDAAA, we employ a difference-in-difference approach with two groups of clinical trials in industry-dominated indications (treated group) vs. in academic-dominated indications (control group). We classify an indication as industry-dominated if the fraction of industry-sponsored projects is greater than one half. We note that these classifications are done using an extended sample including academic projects additionally, while all our regression analyses afterwards only use industry-sponsored projects. With this approach, we preclude the concern that academic projects are fundamentally different from industry-sponsored projects. ${ }^{6}$

\footnotetext{
${ }^{5}$ Our control variables include the existence of a partner for a given project, a given drug developer's total number of projects, project diversification, percentage of matured projects, and percentage of projects with partners, and a given indication's total number of competitors and percentage of matured projects,

${ }^{6}$ Comparing patenting activities of university R\&D with government vs. industry grants, Babina et al. (2020) show that federal funding leads to fewer but more general patents.
} 
Our difference-in-differences results not only alleviate the concern that our findings may be driven by any commingled factor unrelated to the FDAAA, but also support that the increased amount of information is indeed the main driver of increased suspensions. We also implement robustness checks to ensure that our findings are not driven by financial crisis in 2008-2009, strategic terminations of projects involving M\&As (Cunningham, Ederer, and Ma, 2019), and the sample selection excluding phases inapplicable to the FDAAA.

We propose that the post-FDAAA increase in suspension rates can be attributed to three mechanisms that may co-exist: learning and competition mechanisms (see Reinganum, 1984), and the interaction of financial constraints and market sentiment. First, pharmaceutical firms can learn from their peers' public disclosures and update their information sets regarding the viability and prospect of their own clinical trials. With more frequent and detailed information updates, especially on unsuccessful outcomes, those firms will be more likely to suspend projects that are not promising (Fudenberg, Gilbert, Stiglitz, and Tirole, 1983; Harris and Vickers, 1985; Cockburn and Henderson, 1994). Second, when pharmaceutical firms compete to develop new drugs for the same disease, the first new drug to be approved may enjoy market advantages and preempt others. Therefore, information on unsuccessful outcomes of a firm increases other firms' expected profits and reduces their incentives to suspend their related projects (Scherer, 1967; Loury 1979; Dasgupta and Stiglitz, 1980a, 1980b). Third, after the FDAAA, drug developers can no longer hide unsuccessful clinical trial outcomes from the public; thus, outside investors may become less supportive to public pharmaceutical firms when they observe unsatisfactory outcomes (Mace, 2019).

Further analyses support the peer learning mechanism: the suspension decision of only lowquality firms and firms without partners is significantly dependent on peers' failures after the FDAAA. These results conform with information spillovers from peers' experience, especially on fundamental difficulties and complications that cause failures. On the other hand, these results are inconsistent with the competition mechanism that predicts a decrease in the suspension likelihood with peers' failures. We further find that the post-FDAAA increase in suspension is significant regardless of the degree of competition. Moreover, we find similar magnitudes of the effects between financially constrained and unconstrainted firms and between private and public firms. This finding does not support an explanation based on financial constraints and market sentiment. 
In our last set of empirical tests, we attempt to quantify the social welfare implications. First, we find that the frequency of adverse events of a drug significantly reduces by about $56 \%$ after the FDAAA. ${ }^{7}$ Second, the likelihood of a drug to deliver serious adverse events decreases by 5 to $9 \%$ after the FDAAA. These results are consistent with the interpretation that firms are more likely to suspend high risk projects due to their increased efficiency in making suspension decisions with enhanced information disclosure.

Nevertheless, there are also downsides associated with the FDAAA. The enhanced information disclosure reduces the expected NPV of some future new drug projects, which prevents firms from initiating such projects. Also, faster diffusion of information about ongoing new drug development may motivate firms to give up some projects too early, even though those can be improved with more time and effort. ${ }^{8}$ For example, our evidence shows that the annual growth rate of active projects is approximately $25 \%$ before the FDAAA but becomes negative after the FDAAA. To examine this social welfare implication, we compare Disability-Adjusted Life Years (DALYs, the number of years lost due to a given disease) from World Health Organization (WHO) between the two indication groups that experience high and low growth in the number of clinical trials around the FDAAA. We find that if the low-growth group receives the same investment as the high-growth group does, then the DALY of the low-growth group may also drop by the same magnitude $(8.27 \%)$, which is 7.6 million years. These possible drawbacks call for further analysis of the optimal degree of information disclosure in the pharmaceutical industry. ${ }^{9}$

Overall, our study provides new evidence for the effect of information disclosure on investment in innovation. Previous empirical evidence of the effect is limited (see for example Williams, 2017; Brown and Martinsson, 2017) and subject to the identification challenge (Williams, 2013; Hegde and Luo, 2017; Kim, 2019). The enactment of the FDAAA mandates information disclosure of pharmaceutical firms and is found to have a negative effect on firms' investment as measured by the continuation of projects. These findings are consistent with the model implications of Scotchmer and Green (1990) and Anton and Yao (1994). Our analysis on how a firm's peers learn

\footnotetext{
${ }^{7}$ The frequency of adverse events is defined as the total number of reports in the Adverse Event Reporting System (AERS) that are designed to monitor drug safety for all approved drug and biologic products.

${ }^{8}$ It is common in the literature that individual firms' profit-maximizing decisions may not be socially optimal. Underinvestment in R\&D is a prominent example (Hall and Lerner, 2010).

${ }^{9}$ Prior studies have examined the optimal design for patent protection (see e.g., Gilbert and Shapiro (1990), Matutes et al. (1996), Goh and Oliver (2002), and Hall (2007)).
} 
from its disclosure of clinical trial details also adds to the emerging literature on pharmaceutical firms' reactions to public disclosures (Krieger, 2017; Krieger et al. 2018). ${ }^{10}$

Moreover, our investigation highlights the intended and unintended consequences of the FDAAA. Whereas more industry-sponsored projects are registered and their study details are disclosed in ClinicalTrials.gov after the Act, increased project suspensions follow. This finding is novel to the literature and relevant for policy makers and the general public. Furthermore, we find such reduction can be attributed to learning from peers' trial results, especially unsuccessful outcomes. We also quantify the social welfare implications: the FDAAA enhances the safety of new drugs as reflected in the reduced frequency and likelihood of adverse events after the FDAAA. Nevertheless, the FDAAA disincentivizes firms to continue or initiate new projects at the same time. $^{11}$

\section{Data and Variable Construction}

\subsection{Data sources}

We use the BMT database to obtain our primary sample. The BMT database covers project-level drug development processes for all publicly and privately held firms in the drug industry sector. The database catalogues drug development events since the 1950s, drawing from multiple sources including the FDA approval database, company filings with the Securities Exchange Commission (SEC), conference calls, press releases, news articles, medical conferences, direct communication

\footnotetext{
${ }^{10}$ Prior studies have shown how firms learn from their industry rivals' successes and failures (Madsen and Desai, 2010; Baum and Dahlin, 2007; Kim and Miner, 2007; Ingram and Baum 1997, Haunschild and Sullivan, 2002; Magazzini et al., 2012; Garzon-Vico, 2012). More recently, Bustamante and Fresard (2017) show that firms in imperfect information environments use their peers' investments to update their own estimations about their fundamentals. Prior studies in general show that information disclosure in competitive environments has positive effects on subsequent innovation (Henderson and Cockburn, 1994; Ederer, 2013; Bloom et al., 2013; Boudreau and Lakhani, 2015). However, there are also studies showing negative effects on subsequent innovation: (i) disclosure in technological advance deters R\&D competition as rivals are less likely to develop and patent competing innovations (James, 2011); (ii) firms overreact to news about competition and technological failure with an increase in project exit rates (Krieger, 2017); and (iii) negative shocks to a competitor's drug lead competing firms to move resources away from affected areas and into more exploratory projects (Krieger et al., 2018).

${ }^{11}$ This result shows that the FDAAA might have unintended consequences of the FDAAA and ought to draw attention from policy makers. A few recent studies examine the consequences of additional disclosure from the FDAAA but focus on an individual firm's information environment, such as reduced information asymmetry (Bourveau et al., 2017) and increased forecast accuracy (Hao et al., 2017). However, none of them examines the consequences on aggregate innovative activities following increased information transparency and social welfare implications. On the other hand, prior studies have documented the social welfare implications by examining the effects of patent disclosure on knowledge diffusion and innovations (e.g., Aoki and Spiegel, 1998; Johnson and Popp, 2001; Budish et al., 2015; Galasso and Schankerman, 2015; Graham and Hegde, 2015; Hedge and Luo, 2017). In addition, the patent system mitigates overlapping R\&D efforts that are costly to society (Kamien and Schwartz, 1975; Stephan, 1996).
} 
with companies, and the ClinicalTrials.gov database. The ClinicalTrials.gov database provides superb information that includes detailed study designs and outcomes of all registered clinical trials, but its data only start in 2005 following the ICMJE. (Appendix B shows an example of the detailed study report for a drug in phase 2 from ClinicalTrials.gov.) The FDA also publishes comprehensive information about approved drugs, but not about current projects under development. Unlike the FDA approval database, the BMT contains information on all projects under development including the specific development phase and outcome for each project phase. However, the information from the BMT is limited to the occurrences of events and does not include detailed study designs and outcomes of clinical trials. From BMT, we obtain the suspension variable and variables for phase advances, partnered projects, indications, and peer projects in the same indication.

Figure 1-(a) shows that the total number of registered clinical trials has been increasing over time but with a slowdown in the increase after the FDAAA. Figure 1-(b) shows that the average number of progress updates per projects was around 1.2 before the FDAAA and has significantly increased in the more recent period after the FDAAA.

\section{[Insert Figure 1 Here]}

Drug development is regulated by the FDA requirements. The process is divided into parts: pre-clinical research on micro-organisms and animals, and clinical trials - which include phases 1, 2, and 3 - on humans. ${ }^{12}$ During the pre-clinical stage, laboratories pinpoint new compounds and companies perform safety testing for phase 1. An Investigational New Drug (IND) application is then submitted to the FDA; this application details the effects of the active ingredients and toxicities of a drug. After the IND receives approval, the development advances to the three clinical phases involving human subjects. ${ }^{13}$

\footnotetext{
${ }^{12}$ During phase 1, safety and dosing concerns are addressed with healthy volunteers. During phase 2, the drug's effectiveness is tested in a relatively small sample of people with a certain disease or condition. During phase 3, largescale trials are conducted to determine the safety and effectiveness of a drug. At the conclusion of phase 3, a New Drug Application (NDA) or Biologic License Application (BLA) is submitted for FDA review and final approval. The FDA reviews all of the data presented with an NDA or BLA and ultimately approves or denies a new drug for the market. We denote all the remaining clinical study phases that include final FDA reviews and approvals as post-phase 3.

${ }^{13}$ An institutional review board (IRB) has the authority to approve, require modifications in, or disapprove research to provide a core protection of human subjects of research in accordance with FDA regulations. The requirement of an independent committee review for any human subject research was codified as federal regulation in 1974 by the National Research Act.
} 
A drug's development can be suspended in the middle of clinical trial phases, for various reasons. Firms can voluntarily suspend or terminate their trials at any point, if their results aren't demonstrating their expected effectiveness, for example. Likewise, firms are not allowed to continue to the next trial phase if trial results are not successful. Further, if regulatory agencies believe that a clinical trial is not meeting applicable regulatory requirements or poses an excessive safety risk to participants, they can suspend the project. Although suspended trials can be resumed with a new or revised clinical trial design, our data indicate that resumption is not a common event.

For our primary sample, we use project-level clinical trial phase data that have been covered by the BMT during the sample period from 2002 to 2012. In particular, we focus on industrysponsored clinical trials and exclude the following: (i) clinical trials for generic drugs, which have low uncertainty and follow different FDA requirements; (ii) clinical trials that are not sponsored by industry (i.e., academic-sponsored drugs); (iii) clinical trials in phase 1, which are not subject to the FDAAA; and (iv) drug projects that were initiated after the FDAAA.

Our final sample encompasses 16,916 industry-sponsored project-year observations; this number includes 7,580 clinical trial-years pre-FDAAA and 9,336 clinical trial-years post-FDAAA. The sample has 637 unique pharmaceutical firms with 3,590 unique drug projects. The relevant SIC codes for these firms are 2834 and 2836 . We do not rigorously restrict our sample to "applicable clinical trials" (ACT) of the FDAAA, because the medical literature has found the definition of ACT, when the FDAAA was initially introduced in 2007, was unclear and thus selecting ACT samples relies on our discretion and conjectures. ${ }^{14}$ However, we apply the clear rule that exempts phase 1 clinical trials and clinical trials for foreign-produced and marketed drugs from ACT to our sample selection procedure.

To study social welfare and policy implications, we use the FDA Adverse Event Reporting System (AERS) data. Appendix C shows examples of adverse event reports for a drug and how we classify different reporting cases. The FDA uses the AERS to monitor adverse events and medication errors of all approved drugs under its own post-marketing safety surveillance program. The FDA receives reports about such events from both health care professionals (e.g., physicians,

\footnotetext{
${ }^{14}$ The FDAAA Final Rule was issued in 2016 to clearly specify which clinical trials are subject to the mandatory reporting on the ClinicalTrials.gov (ACT). For more details, see Zarin et al. (2016).
} 
pharmacists, nurses) and consumers (e.g., patients, family members, lawyers). ${ }^{15}$ We use the number of adverse event reports (AER) for each marketed drug as a proxy for drug quality. We classify reports as serious when the patient outcome is one of the following conditions: death, lifethreatening illness, hospitalization, disability, congenital anomaly, or intervention required to prevent permanent impairment and damage. We classify reports as primary suspect when the drug is reported as a primary suspect in an adverse case (which appears " $\mathrm{S}$ " in the field of "Role" in Appendix C).

To further examine social welfare and policy implications, we use the Disability-Adjusted Life Year (DALY) metric from the WHO Health statistics. This measure quantifies the Burden of Disease from mortality and morbidity. One DALY can be considered one lost year of "healthy" life. DALYs for a specific disease are calculated as the sum of the Years of Life Lost (YLL) due to premature mortality in the population and the Years Lost due to Disability (YLD) for people living with the health condition or its consequences. We use two data points-DALYs from 2000 and 2016 - for the top 20 leading causes of DALY globally. ${ }^{16}$ These two points are the nearest available data to the FDAAA enactment. We then compare the two groups of indications with high and low growth rates of active projects around the FDAAA, which enables us to examine how the FDAAA changes DALYs between the two data points (2000 and 2016) for the two groups.

\subsection{Variable construction}

Our main dependent variable, Suspension, for a proxy for divestment is defined as an indicator that equals one if an announcement of suspension is made for a project in a given year or no progress update is made for the duration longer than a threshold, and zero otherwise. ${ }^{17} \mathrm{We}$ use the $90^{\text {th }}$ percentile of the sample duration for each phase as the threshold. The $90^{\text {th }}$ percentile duration is 5 years for phase 2 and 3 projects and 4 years for post-phase 3 projects. In Figure 2, we illustrate the time-series trend of average suspension rates for each phase. The average suspension rate for

\footnotetext{
${ }^{15}$ Clinical reviewers in the Center for Drug Evaluation and Research (CDER) and the Center for Biologics Evaluation and Research (CBER) evaluate the reports in AERS to monitor the safety of approved products. If reviewers identify a potential safety concern, the FDA may take regulatory actions that include updating a drug's labelling information, restricting use of the drug, communicating new safety information to the public, or removing a product from the market.

${ }^{16}$ The DALY data are available at https://www.who.int/healthinfo/global_burden_disease/estimates/en/index1.html for 2000, 2010, 2015, and 2016. However, the indication-level DALYs are available only for 2000 and 2016.

${ }^{17}$ For robustness, we also consider Disclosed Suspension, an indicator variable that equals one only if a suspension announcement is made for a project in a given year and zero otherwise. We find qualitatively similar results.
} 
each phase is calculated as the total number of suspended projects in a given year divided by the total number of projects in the year. We find in Figure 2 that suspension rates are stable in all phases before the FDAAA and increase significantly after the FDAAA, especially for phase 2.

\section{[Insert Figure 2 Here]}

The main independent variable in our regression analyses is Post, which is one after the passage of the FDAAA in 2007 and zero otherwise. We are particularly interested in whether the passage of the FDAAA changes information environments and pharmaceutical firms' drug development. The major changes in information environments made by the FDAAA is disclosing study details (such as designs and outcomes) of clinical trials to the general public including competing drug developers.

Panel A of Table 1 presents summary statistics of the variables used in our analyses. Suspension (Indicator) has the mean value of 0.13 indicating that $13 \%$ of the clinical trial projects are suspended in the middle of the development process. On average, $54 \%$ of projects in our sample have partners (Project with Partner), and a firm carries 50\% of its project portfolio with partners (Percent of Projects with Partner). The average of $\log (1+$ Number of Projects) is 2.94 , equivalent to 18 projects. ${ }^{18}$

\section{[Insert Table 1 Here]}

The following control variables are also included in regressions with detailed definitions provided in Appendix D. The diversification index of a firm's project portfolio has a mean of 0.52 (Project Diversification). Also, 9\% of the projects in a firm's project portfolio are matured (i.e., in post-clinical trial phases and denoted by Percent of Matured Projects). The average total number of entities in each indication group in a given year is $17.73(\log (1+$ Number of Competitors $)=$ 2.93). Competing entities include both private and public pharmaceutical firms and academic drug developers. The average percentage of matured projects in an indication in a given year is $12 \%$ (Percent of Indication Matured Projects).

In the analyses that explore possible mechanisms for our results, we consider the measures of peer suspensions and advances as well as the measures of competition. Peer Suspension is a dummy variable that takes one if at least one of peer projects in the same indication as a given

\footnotetext{
${ }^{18}$ The mean and median numbers of total projects per firm for a given year are 7.16 and 3 , respectively. The numbers in the summary statistics of Table 1 are calculated at the project-year level and are thus greater than the mean and median calculated at the firm-year level. We cluster standard errors by firm in all our regression analyses.
} 
project is suspended in a given year. Peer Advance is a dummy variable that takes one if at least one of peer projects in the same indication as a given project has advanced to the next phase in a given year. The peer suspension and advance are both lagged, and their averages during our sample period are approximately $60-70 \%$. High Competition represents indication groups with the total number of projects greater than the sample median. In addition, $82 \%$ of the drug projects are not designated as FDA-expedited programs (Non-Expedited Drugs). ${ }^{19}$

For our analysis of social welfare, we consider the following variables based on adverse event reports (AER). The logs of one plus the number of AER and serious AER, $\log (1+$ Number of AER $)$ and $\log (1+$ Number of Serious AER), are 3.83 and 3.33, respectively. These numbers are equivalent to 45 AER and 27 serious AER with a given drug being a primary suspect. Among approved drugs, $92 \%$ have at least one AER with the drugs being a primary suspect, and $88 \%$ have at least one serious AER with the drugs being a primary suspect.

In Panel B of Table 1, we compare the variables between pre- and post-FDAAA periods. The suspension rate is higher in the post-FDAAA period indicating that firms are more likely to suspend their ongoing projects after the FDAAA. Firms on average have greater numbers of total projects, smaller percentages of matured projects, fewer projects with partners, and greater numbers of competitors in the post-FDAAA period. The percentage of indication matured projects has decreased from $14 \%$ to $10 \%$ after the FDAAA.

\section{The Effect of Enhanced Disclosure on Drug Development}

In the literature, information disclosure is often regarded as a first-order concern when a new mandatory reporting requirement is proposed. However, researchers have yet to conclusively identify the effects of mandatory information disclosure on drug development. In this section, we explore how enhanced information disclosure of clinical trials alters pharmaceutical firms' decisions.

\footnotetext{
${ }^{19}$ For drugs that address an unmet medical need in the treatment of a serious or life-threatening condition, FDA designed expedited programs (Fast track, Breakthrough therapy designation, Priority review, and Accelerated approval) to help ensure that therapies for these conditions are approved and available to patients as quickly as possible. Drugs under these expedited programs are regarded to be in a less competitive environment. More information about expedited programs is available at https://www.fda.gov/files/drugs/published/Expedited-Programs-for-SeriousConditions-Drugs-and-Biologics.pdf.
} 


\subsection{Baseline regressions}

In Table 2, we present the results from our baseline regressions that examine the effects of increased mandatory disclosures through the FDAAA on drug project suspensions. The dependent variable is Suspension (Indicator) that equals one if the project has been suspended in a given year and zero otherwise. ${ }^{20} \mathrm{We}$ note that our definition of project suspension includes no progress update for a long time to mitigate a concern related to strategic delay of bad news. We estimate a linear probability model in Columns 1 and 2 and a probit model in Columns 3 and 4.

[Insert Table 2 Here]

In Columns 1 and 3, we regress Suspension (Indicator) on Post that indicates the post-FDAAA period starting from 2008 without controlling for any other variable except firm, indication, and trial-phase fixed effects. ${ }^{21}$ The significantly positive coefficient of Post implies that the passage of the FDAAA is associated with an increased likelihood of suspension. In Columns 2 and 4, we show that the positive association is robust when we control for characteristics of drug developers and their industries. The effect of the FDAAA on project suspension is economically significant at $17.4 \%$ and $12.6 \%$ as estimated from the linear probability models in Columns 1 and 2, respectively.

In Table A.1 in Internet Appendix, we consider regression models analogous to Table 2 but using an alternative definition of project suspension. We replace Suspension (Indicator) with Disclosed Suspension (Indicator) that equals one only if a suspension announcement is made for a project in a given year and zero otherwise. Our results are robust to this definition. Consistent results using both measures of suspension alleviate the concern that our result can be driven by strategic delay of reporting or the increased duration between progress updates.

We note that there is a potential concern that the enactment of the FDAAA in 2007 is adjacent to the 2008-2009 financial crisis. Therefore, in Table A.2 in Internet Appendix, we consider a more refined sample that completely excludes observations in the five-year event window $[-2,+2]$ that contains the financial crisis period (i.e., observations in 2005, 2006, 2007, 2008, and 2009) or that excludes crisis-period observations in 2008 and 2009. We find that the results are robust to using these more refined samples. In all columns, coefficient estimates for Post are positive and

\footnotetext{
${ }^{20}$ When a project is suspended or finally approved by the FDA in year $t$, it is dropped from our regression sample from year $t+1$.

${ }^{21}$ It is noteworthy that we cannot include project fixed effects in our models because projects that have never been suspended or have been approved will be dropped from our regression sample.
} 
statistically significant at the $1 \%$ level. Especially in the first two columns, the sample only includes 2002-2004 and 2010-2012 observations that are least affected by the financial crisis, and we find consistent results. These results effectively rule out the concern that the increase in suspension can be simply attributed to the financial crisis.

Furthermore, in Table A.3 in Internet Appendix, we examine the possibility that effects of the FDAAA can manifest in project initiation decisions. We replace the dependent variable of Table 2 with a measure of project initiation. We consider two sets of regressions; one at the firm-year level with the total number of new projects initiated by a firm as the dependent variable and the other is at the firm-indication-year level with the number of new projects for each indication initiated by a firm as the dependent variable. In all columns, coefficient estimates for Post are negative and statistically significant at the $1 \%$ level. These results suggest that firms cut back their investments significantly by not only suspending existing projects but also avoiding new project initiations.

\subsection{Difference-in-differences regressions: Industry-dominated vs. academic- dominated indications}

Next, we extend our baseline regressions in Table 2 into a difference-in-differences (DID) setting. Specifically, we compare the effect of the FDAAA for projects in industry-dominated vs. academic-dominated indications. We classify an indication as industry-dominated if more than 50 percent of projects in the indication during the sample period are industry-sponsored. Otherwise, we classify an indication as academic-dominated. For this indication-classification purpose only, we append the academic-sponsored project data from ClinicalTrials.gov to our main sample. The average fraction of academic-sponsored projects is $12 \%$ for the industry-dominated group and $64 \%$ for the academic-dominated group. In Table A.4 in Internet Appendix, we present the list of top 30 academic-dominated indications. Cancer is the indication with the largest fraction of academic projects (96\%), and Metabolic - General (90\%), Transplant Rejection (89\%), and Alcohol Dependence (80\%) follow. In terms of the number of projects, Cancer (137) and HIV / AIDS (110) have the most academic projects.

Projects in academic-dominated indications are suitable control observations for those in industry-dominated indications with regards to the changes in information environments due to the FDAAA. Such changes in information environments are expected to be smaller in academic- 
dominated indications than industry-dominated indications, because the clinical trials of academicsponsored projects have been disclosed to the public to a greater extent before the FDAAA in compliance with the ICMJE issued in September 2004. The ICMJE aimed at promoting the disclosure of study details conducted by academic investigators and explicitly mandates submitters to register their clinical trials beyond phase 1 in one comprehensive and publicly available database (such as ClinicalTrials.gov) before journal submissions. For this reason, the FDAAA may not affect disclosure practices of academic-sponsored projects as much as those of industry-sponsored clinical trials. Therefore, we expect that projects in academic-dominated indications face smaller changes in information environments at the time of the FDAAA enactment than projects in industry-dominated indications on average.

We use the same sample of only industry-sponsored projects as in our baseline analysis and divide the sample into the two groups of projects based on indications: industry-dominated (treated) and academic-dominated (control) indications. In Panel A of Table 3, we first report pre-FDAAA summary statistics for the two groups of industry-sponsored projects in industry-dominated and academic-dominated indications. The industry-dominated group have 5,301 indications-year observations that are nearly ten-times greater than 464 indications-year observations in the academic-dominated group.

\section{[Insert Table 3 Here]}

The suspension rates in both groups are similar at 0.04 . We find no statistical difference in suspension rates between the two groups before the FDAAA. Projects in the industry-dominated group are more likely to have partners. The average percentage of projects with partners in a firm's entire project portfolio is also greater for the industry-dominated group although statistically insignificant. Projects in the industry-dominated group are less likely to be in the matured stage, and similarly the percentage of matured projects within indication is smaller for the industrydominated group. Also, there are more competing projects for industry-dominated indications. The different characteristics between industry-dominated and academic-dominated indication groups analyzed in this table are informative for our DID regression design and will be used as control variables.

Panel B of Table 3 reports results from the DID regressions. We focus on the linear probability model for the rest of our analyses because it generates a consistent (unbiased) estimate, even if the dependent variable does not follow a logistic or normal distribution (Wooldridge, 2002). In 
Column 1, we regress Suspension (Indicator) on the interaction term between Post and Industrydominated Indication dummy variables. We include year, firm, phase, and indication fixed effects. Firm fixed effects alleviates the concern that the result is driven by different characteristics of projects chosen by firms. The standalone variable, Post, is subsumed by year fixed effects. We find that the coefficient on the interaction term between Post and Industry-dominated Indication is significantly positive at the $1 \%$ level. This indicates that the effect of the increased mandatory disclosures on suspension rates mainly appears in the industry-dominated group. The economic interpretation of the effect is that projects in industry-dominated indications are $3.8 \%$ more likely to be suspended than those in academic-dominated indications after the FDAAA.

In Column 2, we examine the dynamic DID effects of the FDAAA using year dummy variables: Year $_{[t-3, t-2]}$, Year ${ }_{t-1}$, Year $_{t}$, Year ${ }_{t+1}$, and Year ${ }_{[t+2, t+5]}$. Year $t$ is the indicator for the year 2007, in which the FDAAA is enacted. We find insignificant coefficients on the interaction term of Industry-dominated Indication with Year ${ }_{[t-3, t-2]}$, Year ${ }_{t-1}$, and Year ${ }_{t}$. This result confirms that there is no pre-trend before the passage of the FDAAA and supports the parallel trend assumption underlying the DID test. In addition, the coefficients on the interaction terms with Year ${ }_{t+1}$ and Year ${ }_{[t+2, t+5]}$ are significantly positive. This result suggests that the effect of the increased disclosures on suspension decisions starts right after the enactment of the FDAAA for the industrydominated group and continues afterwards.

In Columns 3 and 4, we consider the analogous tests using indication-level regressions. The dependent variable in these columns is the average suspension rate in each indication instead of the occurrence of the individual project suspension. We find that the results are robust to using indication-level observations and the economic magnitudes are also similar.

Overall, the results with this DID approach mitigate concerns that our findings are driven by any commingled factor unrelated to the increased information disclosure after the FDAAA. We find that projects in industry-dominated indications make suspension decisions differently from those in academic-dominated indications. Thus, these findings especially support a causal implication that changes in information environments following the passage of the FDAAA significantly influence the investment decisions of pharmaceutical companies.

\subsection{Robustness}


Our results could be driven by M\&A waves that possibly coincide with the FDAAA in the pharmaceutical industry. For example, a recent study by Cunningham, Ederer, and Ma (2019) suggests that pharmaceutical firms have an incentive to acquire industry rivals to terminate targets' projects and capture the preemptive advantages in competition. Thus, the increase in suspension after the FDAAA can be caused by such "killer acquisitions" rather than changes in information environments. To rule out this alternative explanation, we limit our sample to projects of firms that experience no M\&A transactions. Table A.5 in Internet Appendix presents the results. ${ }^{22}$ Columns 1 and 2 show results from the linear probability model regressions as in Table 2. Column 3 shows results from the DID regression in Column 1 of Table 3, Panel B using the same sample except that it excludes projects sponsored by firms that experience any M\&A transactions (either as acquirers or targets) in the past three years.

We find that our results remain robust to using a sample free of M\&A transactions. For Columns 1 and 2, coefficient estimates for Post are positive and statistically significant at the $1 \%$ level. In Column 3, we also confirm that our DID result is robust to the exclusion of firms with M\&A transactions. These results indicate that our findings are unlikely to be driven by strategic project terminations involving M\&A activities in the pharmaceutical industry.

We exclude phase 1 projects from our sample, because the FDAAA does not require phase 1 information to be disclosed in ClinicalTrials.gov (i.e., not included in ACT) although firms can voluntarily do so. Also, we exclude projects initiated after the FDAAA from our sample, because firms would have different criteria in choosing projects to initiate after the FDAAA. However, the FDAAA could potentially affect disinvestment decisions of phase 1 projects as post-phase 1 trial outcomes may be correlated with phase-1 investment. Similarly, not to take into account the changes in initiations of the projects after the FDAAA could generate a systematic sample bias.

To alleviate all these concerns, we expand our sample to include clinical trials in all phases and clinical trials that are initiated after the FDAAA. Table A.6 in Internet Appendix shows the results using this extended sample with 23,159 project-year observations. Results in the table are consistent with our findings so far. The baseline regression results in Columns 1 and 2 are similar to the results in Table2. The DID regression result in Column 3 becomes even stronger with a 7.8\% increase in suspension rates for the projects in industry-dominated indications after the FDAAA.

\footnotetext{
${ }^{22}$ We consider the comprehensive global M\&A transactions from the SDC Platinum database where more than 50\% (majority) of equity stakes are acquired.
} 
Overall, robustness tests in this section ensure that our main results are not subject to the sample-bias concern by showing that our findings are not sensitive to the inclusion or exclusion of specific phases or projects.

\section{Mechanisms}

We now explore three explanations for the increased suspension likelihood following the FDAAA. In particular, we focus on the following mechanisms: peer learning vs. competition (Reinganum, 1984), and financial constraints together with market sentiment (Mace, 2019).

\subsection{Learning from peers}

As discussed earlier and shown in the Appendix B, the FDAAA enhances the disclosure of study details of clinical trials. Thus, a firm can make more informed suspension decisions by learning study contents in peer project suspensions (bad news) and phase advances (good news) beyond mere progress updates. This argument suggests that the suspension likelihood will be associated with peer firms' disclosures, and differently so for good vs. bad news. We also examine differential effects by firm quality and the existence of partners. Table 4 reports the regression results for these predictions.

\section{[Insert Table 4 Here]}

We measure peer disclosures on suspensions (Peer Suspension) based on the incidence of suspended peer projects in the same indication as a given project's indication in a given year. Analogously, we measure peer disclosures on advances (Peer Advance) based on the incidence of advanced peer projects in the same indication. These variables are lagged for one year to allow sufficient time for the focal firm to learn.

In Column 1 of Table 4, we find that the coefficient estimate of the interaction term between Peer Suspension and Post is positive and significant at the 5\% level. The economic interpretation is that the suspension likelihood of a project increases by $2.9 \%$ when any peer in the same indication suspends its project in the prior year. We find that the coefficient estimate of the interaction term between Peer Advance and Post is negative but insignificant. These results are consistent with the peer learning mechanism in that the increased details of study contents in compliance with the FDAAA enable firms to learn from their peers' experiences and make 
investment decisions in the same direction. ${ }^{23}$ We note that this learning effect is especially present for negative outcomes of peer projects because suspension events are more frequent in the drug development process and also peers' failures can reveal some fundamental difficulties and complications in the same indication.

In Columns 2 and 3, we further split the sample into low-quality and high-quality firm groups and examine the differential effects between the two groups. ${ }^{24}$ The coefficient estimate for the interaction term between Peer Suspension and Post is still positive and statistically significant at the $10 \%$ level for low-quality firms in Column 2 , whereas that is no longer significant for highquality firms in Column 3. These results suggest that suspensions increase only for low-quality firms after their peer firms disclose suspensions. Whereas, high-quality firms are less likely to respond to information revealed by peer suspension events because they might already have sufficient information for their project's prospect and a good progress to continue.

In Columns 4 and 5, we consider the differential effects by the existence of partners. The coefficient estimate of the interaction term between Peer Suspension and Post is positive and statistically significant at the $5 \%$ level only for firms without external partners in Columns 4 . This is consistent with one of the roles of outside partners being to provide more information on the prospect of a project. Collectively, the results in Table 4 provide supportive evidence to the peer learning mechanism.

\subsection{Competition}

Although the results in the previous section that firms make investment decisions in the same direction as their peers do not support the competition mechanism, we further examine that mechanism in Table 5. Since the FDAAA enhances the disclosure of the details of clinical trial contents, it reduces the information advantage and economic rents for all new drug developers, especially those under fierce competition pressure. We thus test for the prediction that competition makes drug projects to be more likely suspended after the FDAAA. For this test, we consider the following two measures of competition. For Columns 1 and 2, we split the sample into high and

\footnotetext{
${ }^{23}$ To support the competition mechanism discussed in the next section, the coefficient for the interaction term, Peer Suspension (Peer Advance) and Post is expected to be significantly negative (positive).

${ }^{24}$ We define high-quality firms as firms with the total number of phase advances in the past three years is greater than the sample median. Approximately $51 \%$ of the observations in our sample are regarded as high-quality firm observations. Lerner, Shane, and Tsai (2003) show that biotechnology firms rely on the partnership with large companies to fund their R\&D.
} 
low competition groups based on the total number of competing drug projects for each indication. ${ }^{25}$ A project is included in the high competition group if the total number of drug projects in the same indication as a given project's indication in a given year is greater than the sample median and in the low competition group otherwise. For Columns 3 and 4, we use an indicator for whether the project is designated as an FDA-expedited program (i.e., fast track, breakthrough therapy, or orphan drug). If the project is designated as an FDA-expedited program, then it is likely that an abnormally small number of entities are currently developing new treatment for the indication, and competition is thus less severe for these projects.

[Insert Table 5 Here]

We run analogous tests to our baseline regression specification in Column 2 of Table 2. The results in Table 5 show that the effect of FDAAA on suspension is present for both high and low competition groups. We find that the coefficient estimates for Post in the low competition group (Columns 2 and 4) are not far from their counterparts in the high competition group (Columns 1 and 3) and also statistically significant. The difference in coefficient estimates for Post between the high and low competition groups is statistically insignificant with the p-value of 0.22 , while the difference between non-expedited and expedited groups appears to be significant.

Overall, the results in this section show that projects in both high and low competition groups are similarly affected by the FDAAA. These findings complementing the results in Table 4 (see Footnote 23) do not support the competition mechanism.

\subsection{Financial constraints and market sentiment}

Another possible explanation for our finding is that, after the FDAAA, drug developers can no longer hide unsatisfactory outcomes from the public. Different from insider investors such as venture capitalists (VCs) that likely have better knowledge and information about drug development, outside investors in public equity markets are less informed and can only rely on the mandatory disclosures under the FDAAA. Thus, after the FDAAA, outside investors may become less supportive to drug developers when they observe unsatisfactory outcomes of clinical trials; as a result, publicly listed drug developers become more conservative in continuing projects after the FDAAA. Although we show that the FDAAA increased the suspension likelihood mainly through

\footnotetext{
${ }^{25}$ Competing projects include industry-sponsored (both public and private) and academic-sponsored projects in each indication.
} 
the peer learning mechanism, also not through the 2007-2009 financial crisis, we implement two additional tests based on financial constraints and the public listing status.

In Table 6, we examine the relation between financial constraints and the FDAAA effect among public firms. In Column 1 of Table 6, we include the financial constraint index developed by Kaplan and Zingales (1997, "KZ" hereafter) in our baseline regression. We find that our main variable of interest, Post, remains significantly positive after controlling for the KZ index. Next, we examine the role of financial constraints by splitting public firms into subsamples based on the $\mathrm{KZ}$ index and estimating the baseline regression (Table 2) within each subsample. In Columns 2 and 3, we find that Post is positive and statistically significant, regardless of the degrees of financial constraints. The coefficient estimates for Post are 0.170 and 0.131 in high and low constraint subsamples, respectively. These two estimates are not statistically different with a $p$ value of 0.12 . These results suggest that even firms that are not under financial constraints still suspend their projects more often after the FDAAA. This does not support the explanation based on the effects of financial constraints.

\section{[Insert Table 6 Here]}

In Table 7, we use public and private firm statuses to capture market sentiment; when compared to private firms, public firms' failures or suspensions may hurt firm value to a greater extent because they are under greater capital market pressure and media coverage. If market sentiment creates financial constraints and pressure on drug developers' decision making, we expect the magnitudes of the FDAAA effect to be different between public and private firms. We split our sample into public firms (Columns 1 and 2) and private firms (Columns 3 and 4) and run analogous tests to our baseline regression. We additionally include available financial characteristics variables in Columns 2 and 4, which are firm size and R\&D expenses for public firms and the amount of venture capital financing for private firms.

[Insert Table 7 Here]

We find that Post variables for all columns are positive and statistically significant at the 1\% level. Regarding the magnitudes of the effect, we find that coefficient estimates are comparable between public and private firms. Coefficient estimates between public and private firms in Columns 1 and 3 are not statistically different with a $p$-value of 0.15 .

We note that some drug developers may have only one ongoing project. These firms may have no alternative but keep proceeding the project regardless of increased information from peers. 
Moreover, suspension announcement may incur greater costs for these firms than for firms with diversified projects. As a result, including drug developers with a single project in our sample may bias our results. To address this concern, we rerun the regressions in Table 7 after splitting each public and private subsample into firms with a single active project and those with multiple active projects. Table A.7 in Internet Appendix presents the results. We find that the effects are similar in both public and private firm samples after excluding firms with a single project.

Overall, Tables 6 and 7 and Table A.7 in Internet Appendix suggest that the FDAAA effect exists in both financially constrained and unconstrained firms, and in both public and private firm samples. This does not support the explanation of our findings based on financial constraints and market sentiment.

\section{Social Welfare Effects}

In this section, we examine social welfare implications of the higher suspension likelihood driven by the FDAAA. We examine both quality and quantity aspects of drug development before and after the FDAAA. We do not analyze price effects, however, due to the lack of individual drug price data. Although a final conclusion for social welfare implications is hard to be drawn without knowing price effects, our analysis on quality and quantity of drug development offers new evidence and insight on the consequences of mandatory disclosures in terms of innovation activities.

\subsection{Drug quality}

We first examine whether the overall quality of drugs has changed after the increased disclosures through the FDAAA. We use adverse event reports (AER) from the FDA to analyze the quality changes of FDA-approved and thus marketed drugs. We expect the quality of drugs to improve because firms have better knowledge to discontinue projects without promising outcomes that could send bad signals to the market. Table 8 examines this prediction based on annual observations of AER for approved drugs. We restrict our sample to FDA-approved industrysponsored drugs that are initiated and approved in and after 1990, considering that the AERS data start in 2004. The main variable of interest is Project Initiation After FDAAA that is one if the drug project is initiated after the passage of the FDAAA and zero otherwise.

[Insert Table 8 Here] 
For the analysis in Table 8, we merge the approved and marketed drugs from our main sample with the Adverse Event Reporting System (AERS) data provided by the FDA by drug names. The sample period of the AERS data starts in 2004, and thus the sample in Table 8 covers the period from 2004 to 2012. If an approved drug in our main sample has no match with the AERS data for a given year, then we assume the number of AER received in that year is zero. In Columns 1 and 2, we use the total number of AER that a drug has received as a primary suspect in a given year for an inverse measure of the drug's quality. We consider an alternative measure in Columns 3 and 4 by focusing on whether a given report is about serious patient outcomes. Appendix $\mathrm{C}$ illustrates how we classify different AER cases. Columns 1 and 3 only include Years from Approval and firm, indication, and year fixed effects. In Columns 2 and 4, we control for characteristics of drug developers and their industries.

Throughout all columns in Table 8, the coefficient estimates of Project Initiation After FDAAA are significantly negative at the $1 \%$ level, consistent with our prediction. These effects translate into approximately a 56\% decrease in the number of AER if the clinical trial of a drug project is initiated after the passage of the FDAAA. ${ }^{26}$ Considering the average numbers of total and serious AER per year of 45 and 27, respectively, from Table 1, this $56 \%$ decrease is equivalent to receiving 25 and 15 less total AER and serious AER per drug per year. It is worth noting that the inclusion of Years from Approval and year fixed effects in our regressions alleviates the concern that older drugs are more likely to receive a larger number of AER than newer drugs in a year, or conversely that older drugs are safer and thus likely to receive fewer AER.

We next examine the likelihood that a drug will deliver any adverse event after the FDAAA in Table 9 using linear probability models. The dependent variables of the first two columns and the last two columns are indicator variables that are ones if the drug is a primary suspect of an AER and a serious AER in a given year, respectively. Columns 1 and 3 only include Years from Approval and firm, indication, and year fixed effects. In Columns 2 and 4, we control for characteristics of drug developers and their industries. The coefficient estimates of Project Initiation After FDAAA in all columns are negative and significant, suggesting that drugs developed under the FDAAA are less likely to deliver any adverse event. The effects are robust in Columns 2 and 4 when we add control variables. The coefficient estimates in Columns 2 and 4

\footnotetext{
${ }^{26}$ For example, in Column 2, the coefficient estimate of -0.830 is equivalent to $\exp (-0.830)-1=-0.564$.
} 
translate into $4.9 \%$ and $9.2 \%$ decreases in the likelihood of receiving an AER and a serious AER as a primary suspect, respectively.

[Insert Table 9 Here]

The results in Tables 8 and 9 collectively suggest that drugs developed under the increased disclosures due to the FDAAA show a lower frequency of adverse outcomes on the intensive margin and also the likelihood of delivering any adverse outcome on the extensive margin. These results are consistent with our prediction; firms discontinue projects without promising outcomes due to the better knowledge on on-going projects and the higher costs of bad outcomes under more transparent information environments.

\subsection{Burden of Disease}

We now examine the quantity effect, specifically whether the FDAAA has any implication on the Burden of Disease. ${ }^{27}$ The previous evidence in Sections 3 and 4 indicates that the FDAAA and increased disclosures lead to greater suspensions of active projects. Also, Table A.3 in Internet Appendix shows that the effect relates with a decrease in new project initiations as well. The mandatory disclosure requirement not only reduces the economic rents and advantages of first movers but also reduces the incentives for firms to follow and imitate. The society may lose potential remedies for critical diseases if firms avoid taking risk and give up their projects earlier or more often. Therefore, we expect that such a decrease in drug development activities can result in greater Burden of Disease and, thus, negatively influence social welfare.

To test this prediction, we first calculate annual growth rates of active projects numbers (i.e., the number of total projects minus the number of suspended projects) for each indication. Figure 3 plots the average numbers and growth rates of active projects over time. We find that the average number of active projects continuously increases in the pre-FDAAA period, but sharply drops after the FDAAA. The time trend for growth rates also confirms that the FDAAA in 2007 appears to slow down the growth significantly. The pre-FDAAA growth rate is approximately $25 \%$, but this growth collapses to nearly zero and even becomes negative more recently. Together with prior results, Figure 3 points to a significant drop in drug development activities after the FDAAA.

\footnotetext{
${ }^{27}$ The Burden of Disease is the impact of a health problem as measured by financial costs, mortality, morbidity, or other indicators, and is often quantified with Disability-Adjusted Life Years (DALYs), which means the number of years lost due to a given disease.
} 
[Insert Figure 3 Here]

We then focus on indications that intend to take care of the top 20 leading causes (diseases) of the globally measured Disability-Adjusted Life Years (DALYs). We use the two snapshots of 2000 and 2016 by the WHO. These two years are the closest data points available around the FDAAA with detailed indication information. A disease's DALYs combine the years lived with disability and the years of life lost due to that disease (i.e., the greater DALY, the more illness). To further quantify the social welfare loss in DALYs due to the slowdown in drug development activities for those critical conditions, we compare reductions in DALY between high-growth and low-growth indication groups and use the difference as social loss due to the slowdown.

Using the difference between average growth rates before and after the FDAAA, we split indications into two groups: (a) the low-growth indication group if the difference is less than the sample median and (b) the high-growth indication group otherwise. Panel A of Table 10 shows the average differences of projects' growth and suspension rates between pre- and post-FDAAA periods for the two groups. Because the division of groups is based on the first set of statistics presented in Row 1, we see the clear difference between the two groups. In the low-growth group, growth rates of active projects decreased by $46 \%$ after the FDAAA, while those increased by $5 \%$ in the high-growth group. We attribute this decrease in growth rates to the increased suspensions associated with the FDAAA. We confirm this conjecture with the statistics presented in Row 2. We find that in the low-growth group, the increase in suspension rates is indeed $3.8 \%$ higher than that in the high-growth group by $4 \%(7.0 \%$ vs. $3.1 \%)$.

[Insert Table 10 Here]

In Panel B, we then quantify the social costs associated with the decrease in the number of active projects based on DALY. In Rows 1 and 2, we first show DALY statistics for the two groups for the pre-FDAAA period. As we discussed previously, the detailed indication-level DALY are only available from the WHO for two years, 2000 and 2016. We therefore use the former for the statistics representing the pre-FDAAA period and the latter for the post-FDAAA period.

In Row 1, we find that DALY for low- and high-growth groups are 91.900 and 100.542 million years, respectively, in 2000. The difference between the two groups is not statistically significant. Results are similar for the other measure of DALY that uses \% in Row 2. DALY (\%) represents the fraction of DALY attributable to a given disease in DALY. Next, in Rows 3 and 4, we show the difference between 2000 and 2016 for the same statistics. We find that the decrease in DALY 
from 2000 to 2016 is significantly greater for the high-growth group than the low-growth group with both measures. The difference is approximately 19 million years in Row 3 .

In sum, as shown in Row 5, average percentage changes in DALY from 2000 to 2016 are $-8.27 \%$ for the high-growth group and $+4.21 \%$ for the low-growth group. These final statistics suggest that if the low-growth group received the same level of aggregate investment as that of the high-growth group, then the DALY of the low-growth group would have dropped by the same magnitude $(8.27 \% \text {, or } 7.6 \text { million years })^{28}$. This finding, together with our previous findings, suggests that the increased disclosure requirements result in greater suspensions of active projects and, in turn, possibly an increase in the Burden of Disease for our society. These results reflect potential unintended consequences of the FDAAA and thus have important policy implications.

\section{Conclusion}

The role of information disclosure in innovation activities has been an important research topic in the literature. However, there is relatively less empirical evidence. To address this gap, we use a unique policy change, the enactment of Section 801 of the Food and Drug Administration Amendments Act in 2007 (FDAAA), to examine how mandatory disclosure of pharmaceutical firms' clinical trials influences their investments as captured by suspension decisions. Specifically, we find higher suspension rates after the FDAAA, suggesting that increased information transparency reduces pharmaceutical firms' innovative investments. This relation has a causal interpretation based on a difference-in-differences analysis showing that, in comparison with projects in academic-dominated indications, projects in industry-dominated indications are suspended more often after the FDAAA. Moreover, we provide evidence that supports a learningbased explanation for our findings by showing that a firm's suspension decision is associated with peers' detailed suspension disclosures in the same direction after the FDAAA. Therefore, the mandatory disclosure of the FDAAA indeed appears to create information diffusion to peer firms and enable firms to learn from their peers' experiences.

Our empirical investigation has policy and social welfare implications, as it highlights both the intended and unintended consequences of the FDAAA. On the one hand, the original goal of enhancing transparency and safety has been achieved. We indeed find fewer Adverse Event

\footnotetext{
${ }^{28}$ The potential decline in DALY is estimated at 7.6 million years based on the mean DALY for the low-growth group of 91.9 million years.
} 
Reports (AER) per drug after the FDAAA, suggesting an improvement with respect to drug quality. On the other hand, as unintended consequences of enhanced information disclosure, pharmaceutical firms become less motivated to initiate and continue risky projects and are more likely to cut projects that do not deliver good outcomes in earlier stages. Such risk-averse approaches result in fewer new drug projects, which lowers the life quality of the public in the long run. 


\section{Appendix A. Institutional Background of the FDAAA}

The Food and Drug Administration Modernization Act (FDAMA, Section 113) that was passed and enacted in 1997 established the ClinicalTrials.gov database, a website that provides patients, their family members, health care professionals, researchers, and the public with easy access to information on publicly and privately supported clinical trials on serious or life-threatening diseases and conditions. ${ }^{29}$ The website established the protocols of the records of clinical trials in order to disclose design, methods, objectives, relevant scientific background, and statistical information and is maintained by the National Library of Medicine (NLM) at the National Institutes of Health (NIH). FDAMA Section 113 requires summary information about publicly and privately funded clinical trials of investigational new drugs (and biological products) only for serious or life-threatening diseases and conditions (Tse and Zarin, 2009). Voluntary reports from uncovered trials are also accepted.

The most significant change to the disclosure of drug development is Section 801 of FDAAA, which was passed and enacted in 2007 (Tse et al., 2009; Tse and Zarin, 2009) ${ }^{30}$ This act can be regarded as an advancement in information disclosure, following the FDAMA, the ICMJE joint editorial, the Joint Position on the Disclosure of Clinical Trial Information issued by four pharmaceutical industry associations worldwide, and other relevant U.S. and international policies (Tse and Zarin, 2009; Zarin et al., 2016; Lassman et al., 2017). It responds to the call from patient advocacy groups, which have lobbied to help patients gain access to up-to-date information about possible life-saving therapies and addresses the loss of the public's trust in medical literature due to publication bias (Gill, 2012; dos Santos and Atallah, 2015).

\footnotetext{
${ }^{29}$ The history and evolution of the ClinicalTrials.gov database are available at https://clinicaltrials.gov/ct2/about-site. ${ }^{30} \mathrm{https}: / /$ www.congress.gov/bill/110th-congress/house-bill/3580 Title VIII: Clinical Trials Databases - (Sec. 801) Amends the Public Health Service (PHS) Act to require the Secretary, acting through the Director of NIH, to expand the clinical trials registry data bank. 1. Requires the Director to ensure that the data bank is made publicly available through the Internet. Specifies information required to be submitted for an applicable clinical trial and included in the data bank. 2. Requires the Secretary to ensure that the data bank includes links to results information for those clinical trials that form the primary basis of an efficacy claim or are conducted after the drug or device involved is approved or cleared. 3. Requires the Secretary to further expand the registry and results data bank to provide more complete results information and enhance patient access to and understanding of the results of clinical trials within three years after enactment of this Act. 4. Prohibits the failure to submit required clinical trial information or the submission of false or misleading clinical trial information to the data bank. Sets forth civil penalties for violations. 5. Prohibits a state or political subdivision from establishing or continuing in effect any requirement for the registration of clinical trials or for the inclusion of information relating to the results of clinical trials in a database after the required expansion of the data bank three years after enactment of this Act.
} 
The FDAAA amends the Public Health Service (PHS) Act to require the FDA (i) to mandate the expanded scope and additional information of an "applicable clinical trial" (ACT) to be registered in the ClinicalTrials.gov database within 21 days of enrolling the first patient; ${ }^{31}$ in addition, the summary results are required to be filed within a year of a clinical trial's completion date, ${ }^{32}$ (ii) to make the database publicly available through the Internet, and (iii) to establish civil penalties for failure to submit required clinical trial information or for the submission of false or misleading clinical trial information to the database (Tse et al., 2009; Tse and Zarin, 2009). The FDAAA requires sponsors, sponsor-investigators, or sponsor-designated principal investigators of clinical trials to submit information about a clinical study to ClinicalTrials.gov and update that information accordingly. The penalties for noncompliance include the withholding of NIH grant funding and civil monetary penalties of up to $\$ 10,000$.

Overall, the literature suggests that the FDAAA significantly enhanced the information disclosure of clinical trials. Using a sample of 243 clinical trials of specific biological products, dos Santos and Atallah (2015) find that the rate of ClinicalTrials.gov registration increases from $13.6 \%$ before the FDAAA to $70.2 \%$ for trials subject to the mandatory reporting under the FDAAA (and $35.6 \%$ of trials that are not subject to the FDAAA). ${ }^{33}$ Gill (2012) confirms a substantial increase in the number of registered trials in ClinicalTrials.gov since 2007. On the other hand, some studies suggested that the coverage of the database may not be updated in a timely manner;

\footnotetext{
${ }^{31} \mathrm{https}: / /$ clinicaltrials.gov/ct2/manage-recs/fdaaa\#WhichTrialsMustBeRegistered Registration is required for studies that meet the definition of an "applicable clinical trial" (ACT) and either were initiated after September 27, 2007 or initiated on or before that date and were still ongoing as of December 26, 2007. ACTs, as defined in section 402(j) of the PHS Act, include (i) controlled clinical investigations (other than phase 1 investigations) of any FDA-regulated drug or biological product for any disease or condition, and (ii) certain studies of FDA-regulated medical devices, excluding small clinical trials to determine feasibility and certain clinical trials to test prototype devices, but including FDA-required pediatric postmarket surveillances of a device product. For more details definition of applicable clinical trials, see: https://prsinfo.clinicaltrials.gov/ElaborationsOnDefinitions.pdf

${ }^{32} \mathrm{http} / / \mathrm{www}$.atlantclinical.com/compliance-with-fdaaa801 The completion date is the date of the last clinical trial visit of the last patient enrolled in the clinical trial. This deadline, however, can be extended up to 2 years under certain circumstances related to the market's approval of novel products. A certification to delay submission or an extension request must be provided.

${ }^{33}$ On the other hand, the fact that the registration rate of industry-sponsored trials is not close to $100 \%$ can be attributed to several reasons (Miller et al., 2012; Lassman et al., 2017): first, the collaboration among different institutes and the occurrences of mergers and acquisitions make it difficult for the FDA to hold any party responsible for the registration. Second, the coverage of applicable clinical trials of the FDAAA is not well-defined and some descriptions about the registration obligation and deadlines are ambiguous. Third, the delay penalty has not been imposed.
} 
however, such a criticism is denied by the FDA (Hawkes, 2012; Lassman et al., 2017). ${ }^{34}$ All these studies collectively indicate a substantial albeit imperfect coverage of the results of industrysponsored clinical trials after the enactment of the FDAAA. In fact, all the discussions (including criticisms) on the efficacy and consequence of the FDAAA suggest that the FDAAA and its impact on information disclosure were well-perceived and widely discussed among participants; such attention to and awareness of regulation changes naturally increase the pressure to prepare for mandatory disclosures or those that may be mandatory in the future.

The FDAAA was refined in 2016 with the issuance of 42 CFR Part 11 for Clinical Trials Registration and Results Information Submission (i.e., the "Final Rule"), which took effect in January $2017 .{ }^{35}$ The Final Rule aims to clarify the requirements for the regulated parties, interpret ambiguous important statutory provisions, and make decisions about additional reporting requirements necessary (Zarin et al., 2016). In sum, FDAAA 801 essentially requires all clinical trials of new drugs that are under the FDA jurisdiction to be registered on ClinicaTrials.gov within 21 days of enrolling the first patient and also requires summary results (including adverse events) to be reported within a year of clinical trial completion date (Fassbender, 2018).

\footnotetext{
${ }^{34}$ Using a sample of 317 industry-sponsored trials that were completed in 2009 and likely subject to the FDAAA 801, Prayle et al. (2012) find that only $126(40 \%)$ of these had submitted their results to ClinicalTrials.gov on time (i.e., within the one-year period from the completion date). However, the FDA has disagreed with the results reported by Prayle et al. (2012) and pointed out methodological flaws in that study (e.g., including trials not covered by FDAAA, only tracking the on-time registrations) (Hawkes, 2012). In responding to this dispute, the U.S. National Institutes of Health (NIH) implemented an unofficial analysis and reported that $52 \%$ of industry-sponsored trials had filed results on time. In addition, Nguyen et al. (2013) examine a sample of 646 cancer-related trials and find that $31 \%$ of them posted results in ClinicalTrials.gov within three years after the completion date. Anderson et al. (2015) construct a sample of 8,736 industry-funded trials that are completed after 2008 and are highly likely subject to the FDAAA and find that $41.5 \%$ of them reported results at ClinicalTrials.gov by September 2013 (but only $17.0 \%$ were reported ontime). Reexamining the data of Miller et al. (2012), Lassman et al., (2017) focus on 15 novel drugs that were sponsored by big firms and were approved in 2012, and they find that almost all of them fully complied with the FDAAA.

${ }^{35}$ For details, see Zarin et al. (2016).
} 


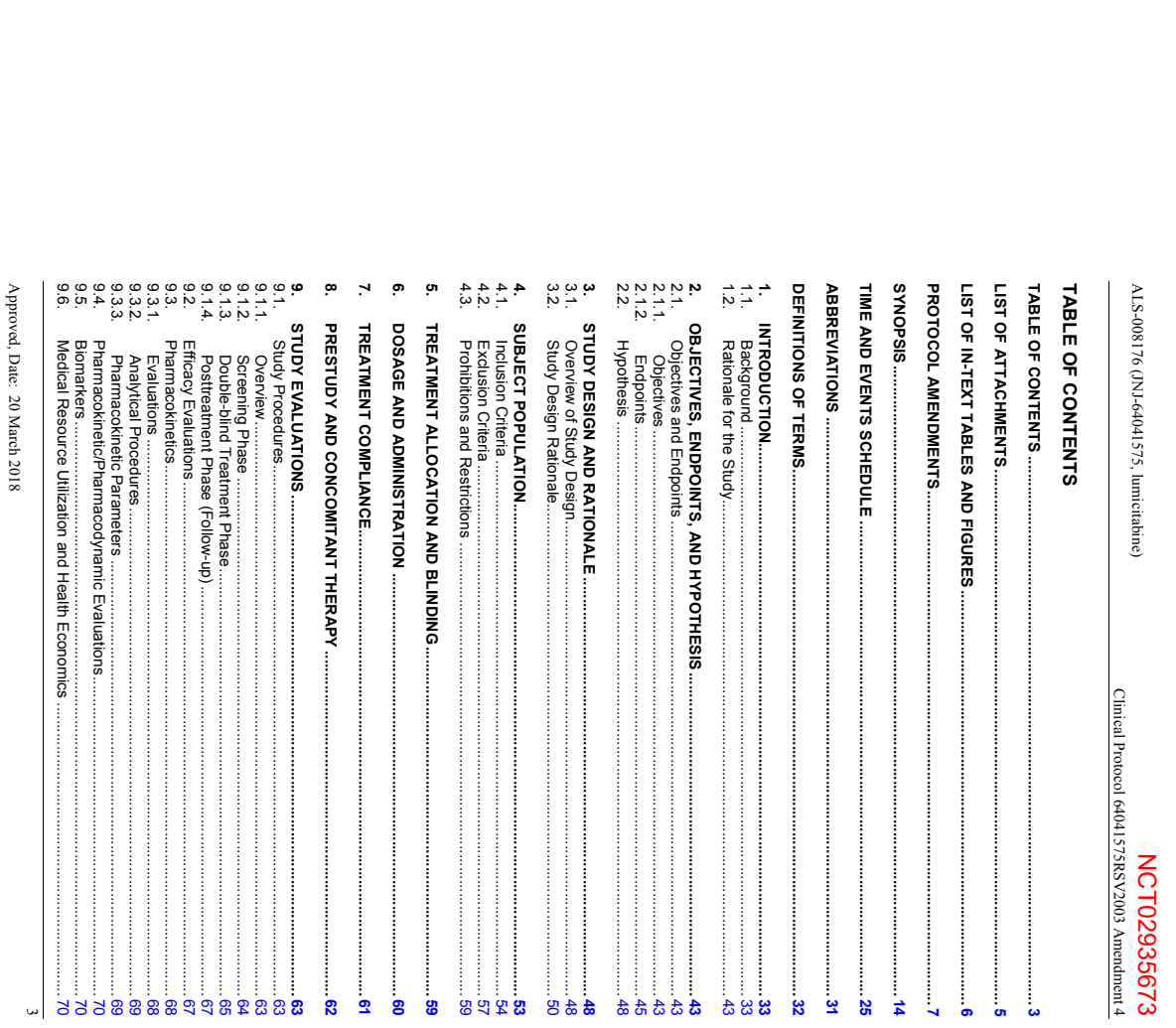

w
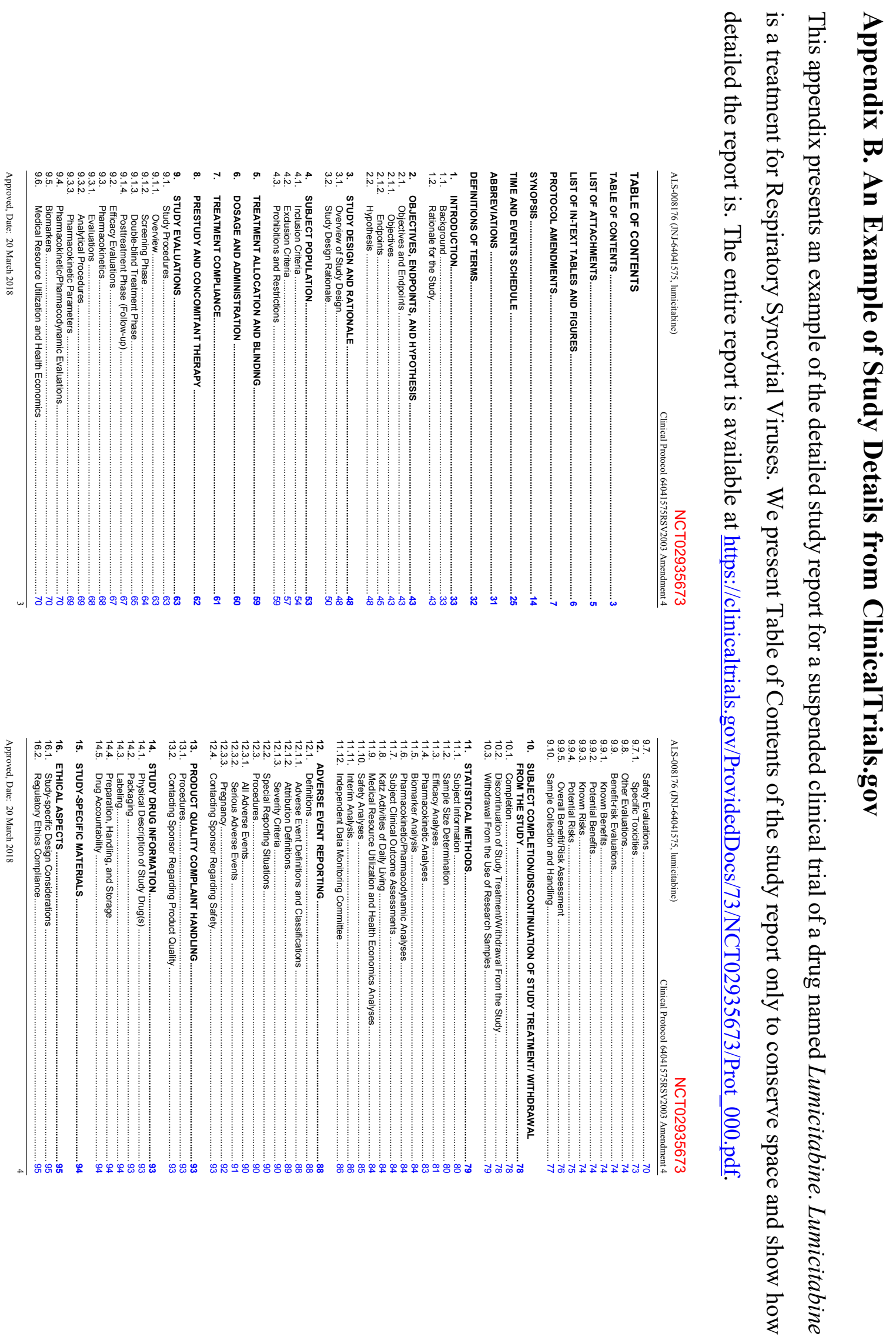


\section{Appendix C. Examples of the FDA Adverse Event Reports}

This appendix presents examples of the FDA adverse event reports for a drug named Androgel. Androgel is a supplement for testosterone. The field, Outcomes, in the table indicates whether the reported outcome is Serious. The outcome categories include congenital anomaly/birth defect (CA), death (DE), disability (DS), hospitalization (HO), life-threatening (LT), other serious important medical event (OT), and required intervention to prevent permanent impairment/damage (RI). A report can state multiple outcomes. If the field is missing, the report is classified as Nonserious. The field, Role, indicates whether the reported drug is Primary Suspect. Suspect (S) identifies products that the initial reporter deemed most likely to be associated with the event, and Concomitant $(\mathrm{C})$ identifies products taken at the same time as the suspect product but not deemed as being associated with the event. The Suspect field can be further classified as Secondary Suspect when needed. In the four adverse event reports shown, for Androgel being a primary suspect, the Number of AER are four, and the Number of Serious AER are three. For Zocor which is reported as a concomitant drug, both the Number of AER and the Number of Serious AER are zero.

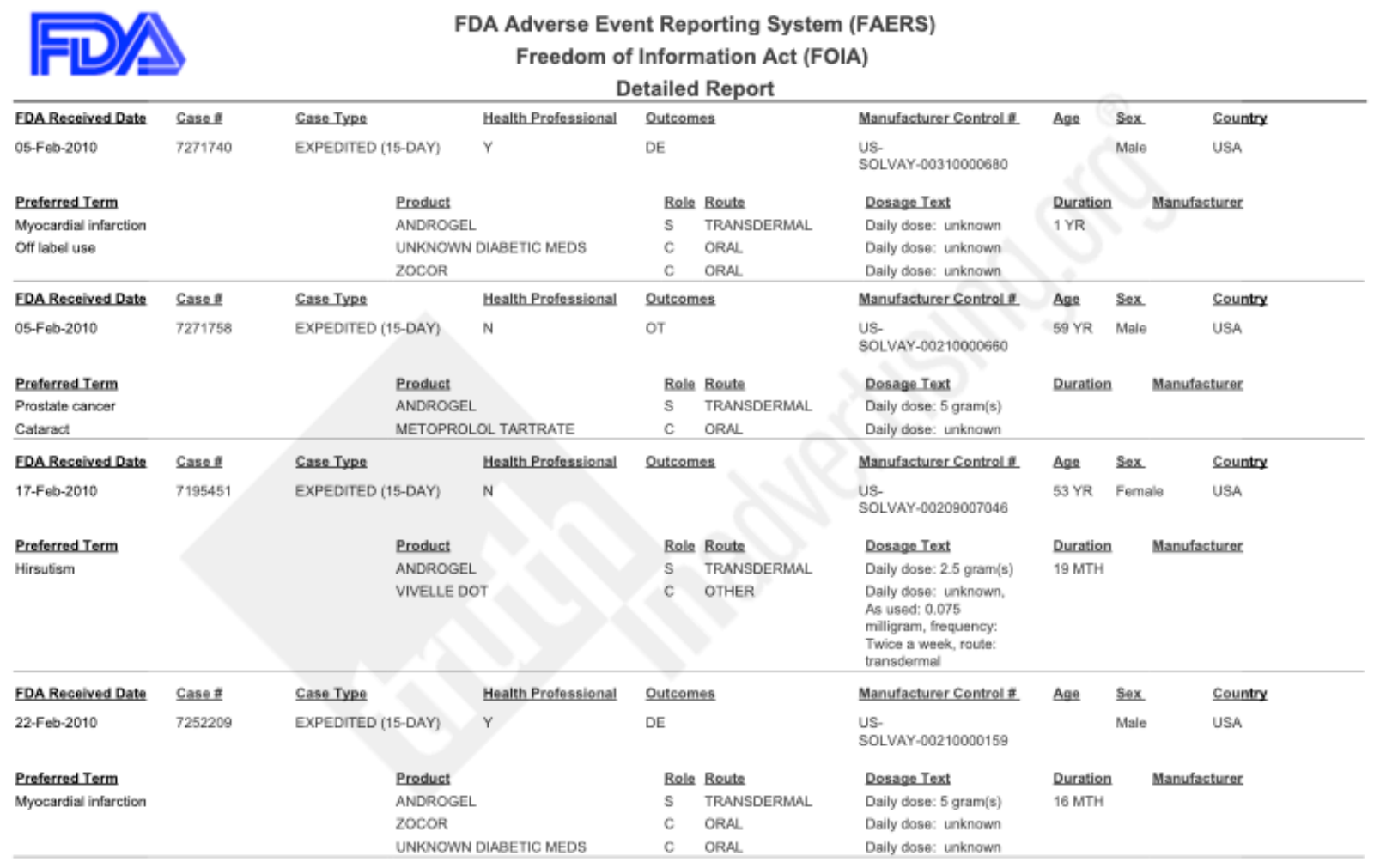




\section{Appendix D. Variable Definitions}

- Suspension (Indicator): An indicator that is one if the project is suspended in a given year or has no progress update for the duration longer than the 90th percentile of the sample duration with the same phase and zero otherwise.

- Disclosed Suspension (Indicator): An indicator that is one if a suspension announcement is made for the project in a given year and zero otherwise.

- Post (Indicator): An indicator that is one after the passage of the FDAAA in 2007 and zero otherwise.

- Project with Partner (Indicator): An indicator that is one if the project has partners in a given year and zero otherwise.

- $\log (1+$ Number of Projects): The log of the total number of drug projects for the firm in a given year.

- Project Diversification: The firm-year level diversification index calculated as one minus the sum of the squared project shares of the disease groups in the firm's pipeline in a given year.

- Percent of Matured Projects: The percentage of matured projects (post-phase 3) in the firm's pipeline in a given year.

- Percent of Projects with Partner: The percentage of the projects in the firm's pipeline that have partners in a given year.

- $\log (1+$ Number of Competitors): The log of one plus the total number of drug developers in each indication in a given year. The entire industry-sponsored (both public and private) and academic-sponsored projects from the preclinical stage to the final FDA approval stage are considered for the variable construction.

- Percent of Indication Matured Projects: The average percentage of matured projects (post-phase 3) in a given year for each indication. The entire industry-sponsored and academic-sponsored projects from the preclinical stage to the final FDA approval stage are considered for the variable construction.

- Peer Suspension (Lagged): An indicator that is one if at least one of peer projects in the same indication as a given project's indication has advanced to a next phase in a given year, excluding the own project's advancement.

- Peer Phase Advance (Lagged): An indicator that is if at least one of peer projects in the same indication as a given project's indication is suspended in a given year, excluding the own project's suspension.

- High Competition (Indicator): An indicator that is one if the total number of projects in the same indication as a given project's indication in a given year is greater than the sample median and zero otherwise.

- Non-Expedited Drugs (Indicator): An indicator that is one if the project is not designated as an FDAexpedited program, which includes fast track, breakthrough therapy, and orphan drug, and zero otherwise.

- Project Initiation After FDAAA (Indicator): An indicator that is one if the project is initiated after the passage of the FDAAA in 2007 and zero otherwise.

- $\log (1+$ Number of AER): The log of one plus the total number of AER in which the drug is reported as a primary suspect in a given year. 
- $\log (1+$ Number of Serious AER): The log of one plus the total number of AER in which the patient outcome is one of the serious conditions (death, life-threatening, hospitalization, disability, congenital anomaly, or required intervention to prevent permanent impairment and damage) and the drug is reported as a primary suspect in a given year.

- Primary Suspect in AER (Indicator): An indicator that is one if the approved drug is identified as a primary suspect in any AER in a given year and zero otherwise.

- Primary Suspect in Serious AER (Indicator): An indicator that is one if the approved drug is identified as a primary suspect in any AER with serious patient outcomes in a given year and zero otherwise.

- Disability-Adjusted-Life-Years (DALY) (years): Sum of the years lived with disability and the years of life lost due to that disease.

- Disability-Adjusted-Life-Years (DALY) (\%): The fraction of DALY (years) attributable to a given disease in DALY (years) for any disease. 


\section{References}

Aoki, Reiko, and Yossi Spiegel. "Public Disclosure of Patent Applications, R\&D, and Welfare." Department of Economics, University of Auckland, 1998.

Anderson, Monique L., Karen Chiswell, Eric D. Peterson, Asba Tasneem, James Topping, and Robert M. Califf. "Compliance with results reporting at ClinicalTrials. gov." New England Journal of Medicine 372, no.11 (2015): 1031-1039.

Anton, James J., and Dennis A. Yao. "Expropriation and inventions: Appropriable rents in the absence of property rights." The American Economic Review (1994): 190-209.

Anton, James J., and Dennis A. Yao. "Little patents and big secrets: managing intellectual property." RAND Journal of Economics (2004): 1-22.

Arora, Ashish. "Licensing tacit knowledge: intellectual property rights and the market for knowhow." Economics of Innovation and New Technology 4, no. 1 (1995): 41-60.

Arrow, Kenneth Joseph. "Economic welfare and the allocation of resources for invention." Readings in Industrial Economics, pp. 219-236. Palgrave, London, 1972.

Arora, Ashish, Andrea Fosfuri, and A. Gambardella. "Licensing in the chemical industry." Conference Paper, Intellectual Property and Industry Competitive Standards, Stanford University. 1998.

Babina, Tania, Alex Xi He, Sabrina Howell, Elisabeth Perlman, and Joseph Staudt. "Does Funding Source Matter for University R\&D? The Effect of Government vs. Industry Grants." Working Paper, Columbia University, 2020.

Baum, Joel AC, and Kristina B. Dahlin. "Aspiration performance and railroads' patterns of learning from train wrecks and crashes." Organization Science 18, no. 3 (2007): 368-385.

Bhattacharya, Sudipto, and Jay R. Ritter. "Innovation and communication: Signalling with partial disclosure." Review of Economic Studies 50, no. 2 (1983): 331-346.

Bloom, Nicholas, Mark Schankerman, and John Van Reenen. "Identifying technology spillovers and product market rivalry." Econometrica 81, no. 4 (2013): 1347-1393.

Boudreau, Kevin J., and Karim R. Lakhani. "'Open" disclosure of innovations, incentives and follow-on reuse: Theory on processes of cumulative innovation and a field experiment in computational biology." Research Policy 44, no. 1 (2015): 4-19.

Bourveau, Thomas, Vedran Capkun, and Yin Wang. " Do Firms Respond to Peer Disclosures? Evidence from Disclosures of Clinical Trial Results." Working Paper, HEC Paris, 2019.

Brown, James R., and Gustav Martinsson. "Does transparency stifle or facilitate innovation?." Management Science 65, no. 4 (2019): 1600-1623.

Budish, Eric, Benjamin N. Roin, and Heidi Williams. "Do firms underinvest in long-term research? Evidence from cancer clinical trials." American Economic Review 105, no. 7 (2015): 2044-85.

Bustamante, Maria Cecilia, and Laurent Frésard. "Does Firm Investment Respond to Peers' Investment?." Working Paper, University of Maryland, 2017. 
Cockburn, Iain, and Rebecca Henderson. "Racing to invest? The dynamics of competition in ethical drug discovery." Journal of Economics and Management Strategy 3, no. 3 (1994): 481519.

Cohen, Wesley M., Richard R. Nelson, and John P. Walsh. "Protecting their intellectual assets: Appropriability conditions and why US manufacturing firms patent (or not). " Working Paper, National Bureau of Economic Research, 2000.

Cunningham, C., Florian Ederer and Song Ma. "Killer acquisitions." Working Paper, Working Paper, Yale University, 2019.

Dasgupta, P. and J. Stiglitz. "Industrial structure and the nature of innovative activity," Economic Journal 90 (1980a): 266-293.

Dasgupta, P. and J. Stiglitz. "Uncertainty, industry structure and the speed of R\&D," Bell Journal, 11 (1980b): 1-28.

De Angelis CD, Drazen JM, Frizelle FA, Haug C, Hoey J, Horton R, Kotzin S, Laine C, Marusic A, Overbeke AJ, Schroeder TV, Sox HC, Van Der Weyden MB. "Clinical trial registration: a statement from the International Committee of Medical Journal Editors." New England Journal of Medicine 351 (2004): 1250-1.

De Angelis CD, Drazen JM, Frizelle FA, Haug C, Hoey J, Horton R, Kotzin S, Laine C, Marusic A, Overbeke AJ, Schroeder TV, Sox HC, Van Der Weyden MB. "Is this clinical trial fully registered?--A statement from the International Committee of Medical Journal Editors." New England Journal of Medicine 352, no. 23 (2005): 2436-8.

dos Santos, Douglas H. Marin, and Alvaro N. Atallah. "FDAAA legislation is working, but methodological flaws undermine the reliability of clinical trials: a cross-sectional study." PeerJ 3 (2015): e1015.

Ederer, Florian. "Incentives for parallel innovation." Working Paper, Yale University, 2013.

Elfenbein, Daniel W. "Publications, patents, and the market for university inventions." Journal of Economic Behavior \& Organization 63, no. 4 (2007): 688-715.

Fassbende, Melissa, 2018. "Transparency on trial: How to navigate FDAAA 801 final rule implementation and compliance. " Apr 5, 2018. Outsourcing-Pharma.com

Ferreira, Daniel, Gustavo Manso, and André C. Silva. "Incentives to innovate and the decision to go public or private." Review of Financial Studies 27, no. 1 (2014): 256-300.

Fudenberg, Drew, Richard Gilbert, Joseph Stiglitz, and Jean Tirole. "Preemption, leapfrogging and competition in patent races." European Economic Review 22, no. 1 (1983): 3-31.

Galasso, Alberto and Mark Schankerman. "Patents and cumulative innovation: Causal evidence from the courts," Quarterly Journal of Economics 130, no. 1 (2015): 317-369.

Garzon-Vico, Antonio. "Learning From Failure and Learning from Success in the Pharmaceutical and Biotech Industry." Academy of Management Proceedings. Academy of Management. Briarcliff Manor, NY, 2012.

Gilbert, Richard, and Carl Shapiro. "Optimal patent length and breadth." RAND Journal of Economics (1990): 106-112. 
Gill, Christopher J. "How often do US-based human subjects research studies register on time, and how often do they post their results? A statistical analysis of the Clinicaltrials.gov database." BMJ open 2, no. 4 (2012): e001186.

Gill, David. "Strategic disclosure of intermediate research results." Journal of Economics \& Management Strategy 17, no. 3 (2008): 733-758.

Goh, Ai-Ting, and Jacques Olivier. "Optimal patent protection in a two-sector economy." International Economic Review 43, no. 4 (2002): 1191-1214.

Graham, Stuart, and Deepak Hegde. "Disclosing patents' secrets." Science 347 no. 6219 (2015): 236-237.

Guo, Re-Jin, Baruch Lev, and Nan Zhou. "Competitive costs of disclosure by biotech IPOs." Journal of Accounting Research 42, no. 2 (2004): 319-355.

Hall, Bronwyn H. "Patents and patent policy." Oxford Review of Economic Policy 23, no. 4 (2007): 568-587.

Hall, Bronwyn H., and Josh Lerner. "The financing of R\&D and innovation." Hall, B. H. and N. Rosenberg (eds.), Handbook of the Economics of Innovation, 609-639, Elsevier-North Holland, 2010.

Hao, Maggie, Dana A. Forgione, Liang Guo, and Hongxian Zhang. "Improvement in clinical trial disclosures and analysts' forecast accuracy: evidence from the pharmaceutical industry." Review of Quantitative Finance and Accounting 49, no. 3 (2017): 785-810.

Harris, Christopher, and John Vickers. "Perfect Equilibrium in a Model of a Race." The Review of Economic Studies 52, no. 2 (1985): 193-209.

Haunschild, Pamela R., and Bilian Ni Sullivan. "Learning from complexity: Effects of prior accidents and incidents on airlines' learning." Administrative Science Quarterly 47, no. 4 (2002): 609-643.

Hawkes, Nigel. "FDA disagrees with BMJ study that found clinical trials were not being reported." (2012): e3277.

Hegde, Deepak, and Hong Luo. "Patent publication and the market for ideas." Management Science 64, no. 2 (2017): 652-672.

Hellmann, Thomas. "The role of patents for bridging the science to market gap." Journal of Economic Behavior \& Organization 63, no. 4 (2007): 624-647.

Henderson, Rebecca, and Iain Cockburn. "Measuring competence? Exploring firm effects in pharmaceutical research." Strategic Management Journal 15, no. S1 (1994): 63-84.

Horstmann, Ignatius, Glenn M. MacDonald, and Alan Slivinski. "Patents as information transfer mechanisms: To patent or (maybe) not to patent." Journal of Political Economy 93, no. 5 (1985): 837-858.

Hughes, John S., and Suil Pae. "Discretionary disclosure, spillovers, and competition." Review of Accounting Studies 20, no.1 (2015): 319-342.

Ingram, Paul, and Joel AC Baum. "Opportunity and constraint: Organizations' learning from the operating and competitive experience of industries." Strategic Management Journal 18, no. S1 (1997): 75-98. 
Jaffe, Adam B. "Real effects of academic research." American Economic Review (1989): 957-970.

James, Sharon D. "Strategic R\&D disclosure and competition." Working Paper, Ohio State University, 2011.

Jansen, Jos. "On competition and the strategic management of intellectual property in oligopoly." Journal of Economics \& Management Strategy 20, no. 4 (2011): 1043-1072.

Johnson, Daniel KN, and David Popp. "Forced out of the closet: The impact of the American inventors protection act on the timing of patent disclosure." Working Paper, National Bureau of Economic Research, 2001.

Judd, Kenneth L. "On the performance of patents." Econometrica 53, no. 3 (1985), 567-585.

Kamien, Morton I. and Nancy L. Schwartz. "Market structure and innovation: A survey." Journal of Economic Literature 13 (1975): 1-37.s

Kaplan, L. and L. Zingales. "Do investment-cash flow sensitivities provide useful measures of financing constraints?" Quarterly Journal of Economics 112 (1997): 169-215.

Kim, Jinhwan. "Mandatory corporate patent disclosures and innovation." Working Paper, Massachusetts Institute of Technology, 2018.

Kim, Ji-Yub, and Anne S. Miner. "Vicarious learning from the failures and near-failures of others: Evidence from the US commercial banking industry." Academy of Management Journal 50, no. 3 (2007): 687-714.

Krieger, Joshua L. "Trials and Terminations: Learning from Competitors' R\&D Failures." Working Paper, Harvard Business School, 2017.

Krieger, Joshua, Xuelin Li, and Richard T. Thakor. "Find and Replace: R\&D Investment Following the Erosion of Existing Products." Working Paper, Harvard Business School, 2018.

Lassman, S. M., Shopshear, O. M., Jazic, I., Ulrich, J., \& Francer, J. "Clinical trial transparency: a reassessment of industry compliance with clinical trial registration and reporting requirements in the United States." BMJ Open 7, no. 9 (2017): e015110.

Lehman, Richard, and Elizabeth Loder. "Missing clinical trial data." BMJ: British Medical Journal (Online) 344 (2012).

Leland, Hayne E., and David H. Pyle. "Informational asymmetries, financial structure, and financial intermediation." Journal of Finance 32, no.2 (1977): 371-387.

Lerner, Josh, Hilary Shane, and Alexander Tsai. "Do equity financing cycles matter? Evidence from biotechnology alliances." Journal of Financial Economics 67.3 (2003): 411-446.

Levin, Richard C., Alvin K. Klevorick, Richard R. Nelson, Sidney G. Winter, Richard Gilbert, and Zvi Griliches. "Appropriating the returns from industrial research and development." Brookings papers on economic activity 1987, no.3 (1987): 783-831.

Loury, Glenn C. "Market Structure and Innovation," Quarterly Journal of Economics 93 (1979): 395-410.

Madsen, Peter M., and Vinit Desai. "Failing to learn? The effects of failure and success on organizational learning in the global orbital launch vehicle industry." Academy of Management Journal 53, no. 3 (2010): 451-476. 
Mace, Christopher. "The Real Effects of Secondary Markets on Innovation.” Working Paper, University of Utah, 2019.

Magazzini, Laura, Fabio Pammolli, and Massimo Riccaboni. "Learning from failures or failing to learn? Lessons from pharmaceutical R\&D." European Management Review 9, no.1 (2012): 45-58.

Matutes, Carmen, Pierre Regibeau, and Katharine Rockett. "Optimal patent design and the diffusion of innovations." RAND Journal of Economics 27, no.1 (1996): 60.

Merges, Robert P. "A transactional view of property rights." Berkeley Tech. LJ 20 (2005): 1477.

Miller, J.E., Korn, D., Ross, J.S. 2012. "Clinical trial registration, reporting, publication and FDAAA compliance: a cross-sectional analysis and ranking of new drugs approved by the FDA in 2012." BMJ Open 5, no. 11 (2015): e009758.

Nguyen, T. A. H., Dechartres, A., Belgherbi, S., \& Ravaud, P. "Public availability of results of trials assessing cancer drugs in the United States." Journal of Clinical Oncology 31, no. 24 (2013): 2998-3003.

Pajak, Serge. "Do Firms Rely on Big Secrets? An Analysis of IP Protection Strategies with the CIS 4 Survey." ENST Telecom ParisTech, Department of Economics (2009).

Prayle AP, Hurley MN, Smyth AR. "Compliance with mandatory reporting of clinical trial results on ClinicalTrials.gov: cross sectional study." BMJ 344 (2011):d7373.

Reinganum, Jennifer F. "Practical implications of game theoretic models of R\&D." American Economic Review 74, no. 2 (1984): 61-66.

Romer, David. "A simple general equilibrium version of the Baumol-Tobin model." The Quarterly Journal of Economics 101, no. 4 (1986): 663-685.

Sampat, Bhaven and Heidi Williams. "How do patents affect follow-on innovation? Evidence from the human genome," American Economic Review 109, no. 1 (2019): 203-36.

Scherer, F.M. "Research and Development Resource Allocation Under Rivalry," Quarterly Journal of Economics 81 (1967): 359-394.

Solow, Robert M. "Technical change and the aggregate production function." Review of Economics and Statistics 39, no. 3 (1957): 312-320.

Stephan, Paula E. "The economics of science", Journal of Economic Literature 34, no. 3 (1996): 1199-1235.

Tse, Tony, Rebecca J. Williams, and Deborah A. Zarin. "Update on registration of clinical trials in ClinicalTrials. gov." Chest 136, no. 1 (2009): 304-305.

Tse T, Zarin DA. "Clinical trial registration and results reporting: ClinicalTrials.gov and FDAAA." FDLI Update 1 (2009): 18 -22.

Williams, H. "Intellectual property rights and innovation: Evidence from the human genome." Journal of Political Economy 121 no. 1 (2013):1-27.

Williams, H. "How Do Patents Affect Research Investments?" Annual Review of Economics 9 (2017): 441-469.

Wooldrige, J. Econometric Analysis of Cross Section and Panel Data. MIT Press. Cambridge, Massachusetts, 2002. 
Zarin, D. A., Tse, T., Williams, R. J., \& Carr, S. "Trial reporting in ClinicalTrials.gov-the final rule." New England Journal of Medicine 375, no. 20 (2016): 1998-2004.

Zarin DA, Ide NC, Tse T, Harlan WR, West JC, Lindberg DA. "Issues in the registration of clinical trials." JAMA 297 (2007): 2112-20. 


\section{Figure 1. Pre- and Post-FDAAA Trends of Clinical Trials and Disclosures}

The figures present the time trends of clinical trials from 2001 to 2013. Figure (a) shows the total number of clinical trials. The number of clinical trials includes all ongoing projects that are not suspended. A suspended project is a project that is publicly disclosed as terminated or has no progress update for the duration longer than the 90th percentile of the sample duration with the same phase. Figure (b) shows the average number of progress updates (e.g., trial initiation, progress update, trial progressing, updated results) per project. The frequency of progress updates can vary across trials.

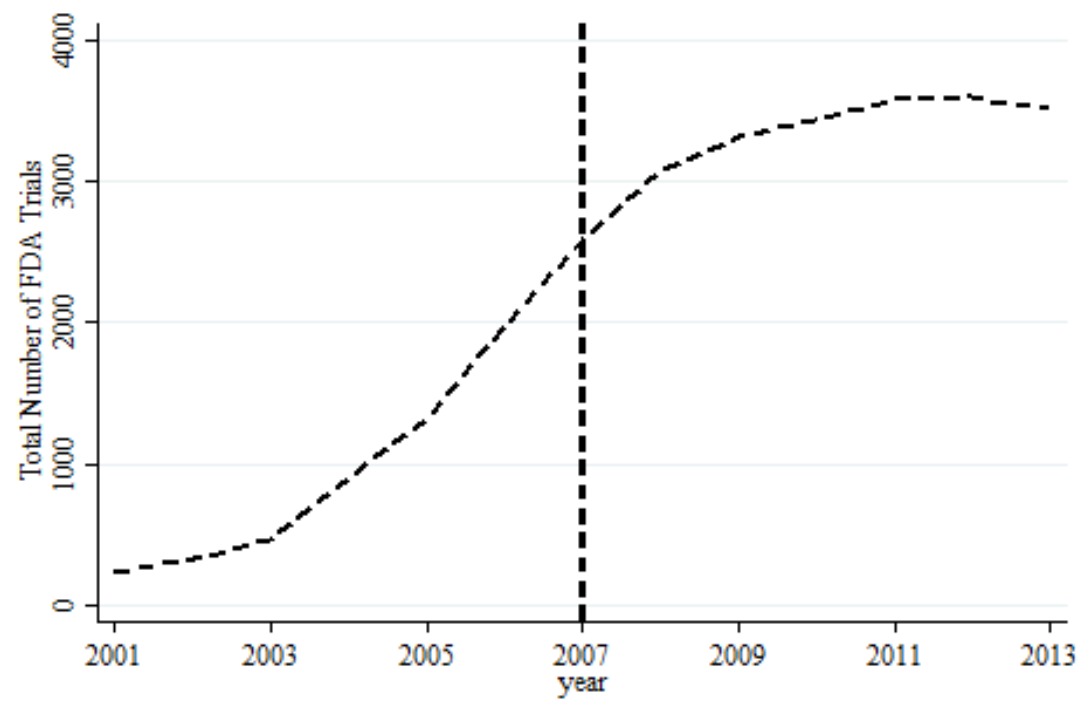

(a) The number of clinical trials

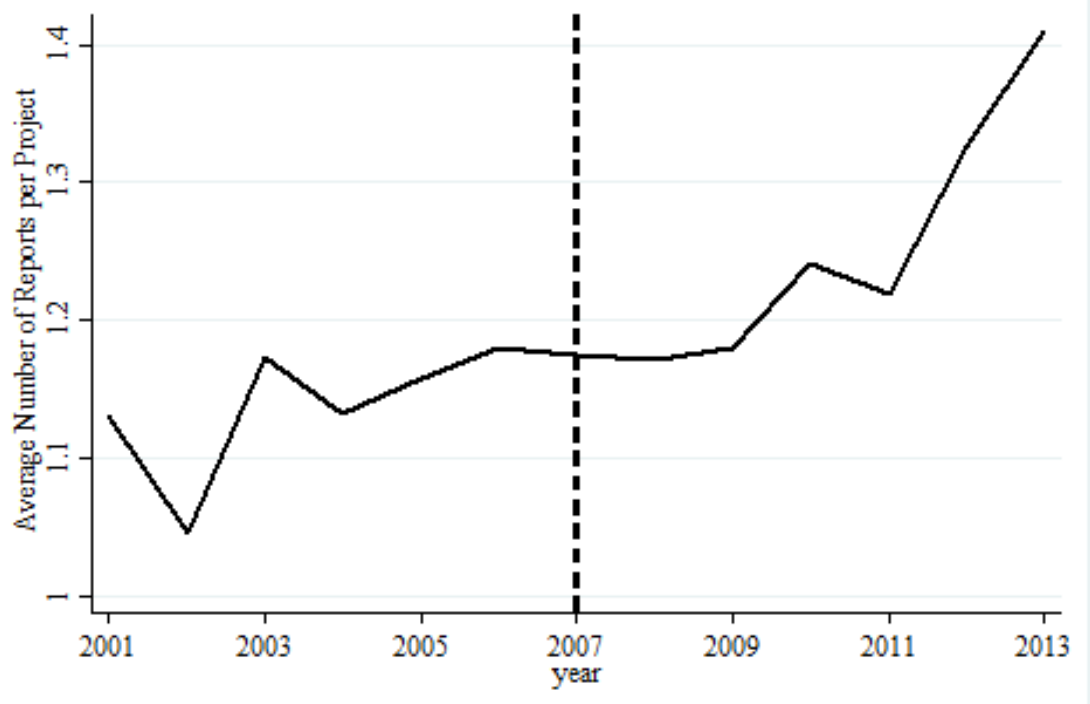

(b) Disclosure intensity 


\section{Figure 2. Pre- and Post-FDAAA Trends of Project Suspension Rates}

The figure presents the time trends of clinical trial suspensions from 2001 to 2013. Each line shows the average suspension rate (i.e., the total number of suspension events divided by the total number of projects in a given year) for each phase.

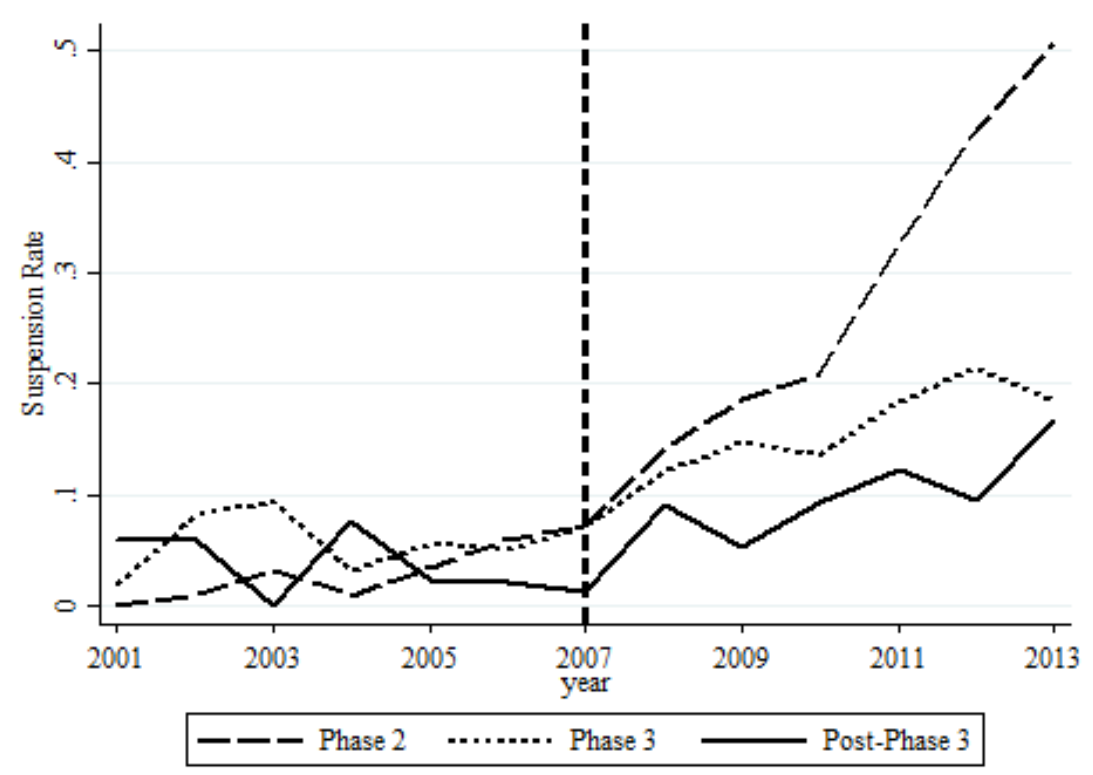




\section{Figure 3. Pre- and Post-FDAAA Number and Growth of Active Projects}

The figure presents the time trends of the average number and growth rate of active projects within indication from 2001 to 2013 . The number of active projects is the total number of projects minus the number of suspended projects in a given year for a given indication. The growth rate is the percentage growth in the number of active projects for a given indication, which is the number of active projects in the prior year divided by the number of active projects in a given year minus one.

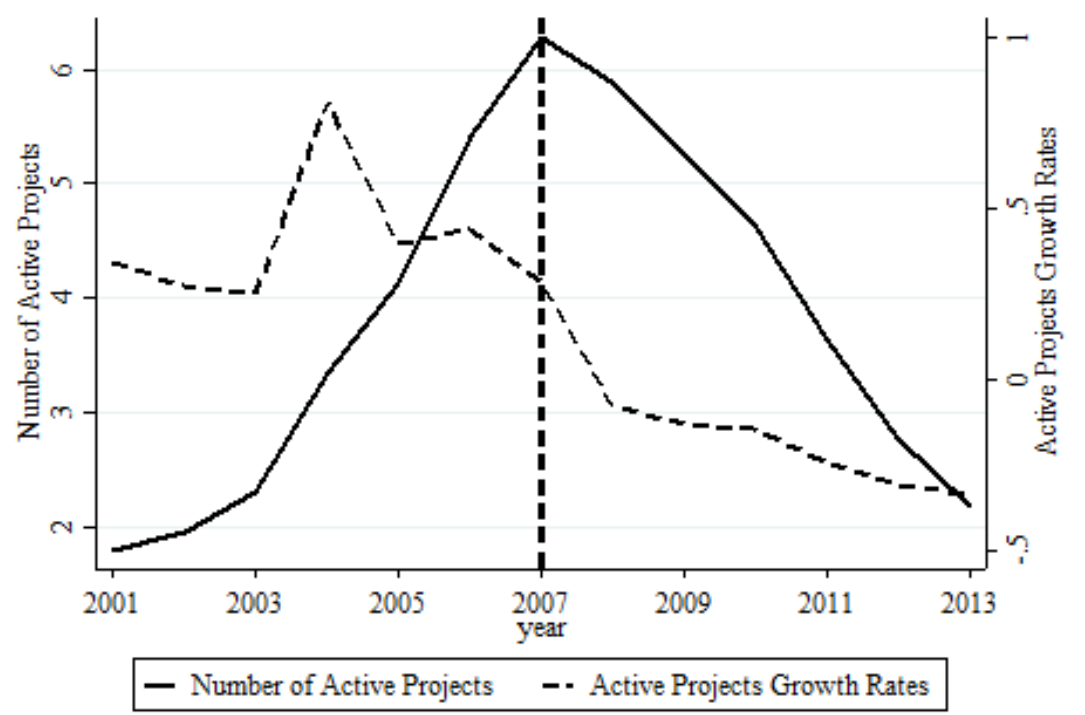




\section{Table 1. Descriptive Statistics}

The table presents summary statistics for our sample in Panel A and compare variables used in regressions between the pre- and post-FDAAA periods in Panel B. The sample consists of 16,916 project-year observations from the BioMedTracker database for our sample period from 2002 to 2012. We exclude the following clinical trials from our sample: (i) clinical trials for generic drugs; (ii) clinical trials that are not sponsored by industry (i.e., academic-sponsored drugs); (iii) phase 1 trials, which are not subject to the FDAAA; and (iv) trials initiated in the post-FDAAA period. Suspension (Indicator), our main dependent variable, is an indicator variable that is one if the project is suspended in a given year or has no progress update for the duration longer than the 90th percentile of the sample duration with the same phase and zero otherwise. The detailed descriptions of other variables are available in Appendix D.

Panel A. Summary Statistics

\begin{tabular}{|c|c|c|c|c|c|c|c|}
\hline & & Mean & SD & Min & Median & Max & Obs \\
\hline \multicolumn{2}{|l|}{ Suspension (Indicator) } & 0.13 & 0.33 & 0.00 & 0.00 & 1.00 & 16,916 \\
\hline \multicolumn{2}{|l|}{ Project with Partner (Indicator) } & 0.54 & 0.50 & 0.00 & 1.00 & 1.00 & 16,916 \\
\hline \multicolumn{2}{|l|}{ Log(1+Number of Projects $)$} & 2.94 & 1.44 & 0.69 & 2.77 & 5.61 & 16,916 \\
\hline \multicolumn{2}{|l|}{ Project Diversification } & 0.52 & 0.31 & 0.00 & 0.63 & 0.90 & 16,916 \\
\hline \multicolumn{2}{|l|}{ Percent of Matured Projects } & 0.09 & 0.16 & 0.00 & 0.04 & 1.00 & 16,916 \\
\hline \multicolumn{2}{|l|}{ Percent of Projects with Partner } & 0.50 & 0.30 & 0.00 & 0.50 & 1.00 & 16,916 \\
\hline \multicolumn{2}{|l|}{$\log (1+$ Number of Competitors $)$} & 2.93 & 1.10 & 0.69 & 3.04 & 5.19 & 16,916 \\
\hline \multicolumn{2}{|l|}{ Percent of Indication Matured Projects } & 0.12 & 0.18 & 0.00 & 0.05 & 1.00 & 16,916 \\
\hline \multicolumn{2}{|l|}{ Peer Suspension (Lagged) } & 0.60 & 0.49 & 0.00 & 1.00 & 1.00 & 12,808 \\
\hline \multicolumn{2}{|l|}{ Peer Advance (Lagged) } & 0.70 & 0.46 & 0.00 & 1.00 & 1.00 & 12,808 \\
\hline \multicolumn{2}{|l|}{ High Competition (Indicator) } & 0.59 & 0.49 & 0.00 & 1.00 & 1.00 & 16,916 \\
\hline \multicolumn{2}{|l|}{ Non-Expedited Drugs (Indicator) } & 0.82 & 0.39 & 0.00 & 1.00 & 1.00 & 16,916 \\
\hline \multicolumn{2}{|l|}{$\log (1+$ Number of AER $)$} & 3.83 & 2.30 & 0.00 & 3.83 & 10.30 & 6,853 \\
\hline \multicolumn{2}{|l|}{$\log (1+$ Number of Serious AER $)$} & 3.33 & 2.22 & 0.00 & 3.26 & 9.95 & 6,853 \\
\hline \multicolumn{2}{|l|}{ Primary Suspect in AER (Indicator) } & 0.92 & 0.27 & 0.00 & 1.00 & 1.00 & 6,853 \\
\hline \multicolumn{2}{|c|}{ Primary Suspect in Serious AER (Indicator) } & 0.88 & 0.32 & 0.00 & 1.00 & 1.00 & 6,853 \\
\hline \multicolumn{8}{|l|}{ Panel B. Univariate Analysis } \\
\hline & \multicolumn{3}{|c|}{ Pre-FDAAA } & \multicolumn{3}{|c|}{ Post-FDAAA } & \\
\hline & Mean & Median & Obs & Mean & Median & Obs & Diff \\
\hline Suspension (Indicator) & 0.05 & 0.00 & 7,580 & 0.19 & 0.00 & 9,336 & $-0.14 * * *$ \\
\hline Project with Partner (Indicator) & 0.55 & 1.00 & 7,580 & 0.52 & 1.00 & 9,336 & $0.03 * * *$ \\
\hline Log(1+Number of Projects $)$ & 2.73 & 2.64 & 7,580 & 3.10 & 2.94 & 9,336 & $-0.37 * * *$ \\
\hline Project Diversification & 0.53 & 0.64 & 7,580 & 0.52 & 0.63 & 9,336 & 0.00 \\
\hline Percent of Matured Projects & 0.13 & 0.09 & 7,580 & 0.06 & 0.03 & 9,336 & $0.08 * * *$ \\
\hline Percent of Projects with Partner & 0.54 & 0.54 & 7,580 & 0.48 & 0.48 & 9,336 & $0.06^{* * *}$ \\
\hline Log(1+Number of Competitors) & 2.51 & 2.56 & 7,580 & 3.27 & 3.40 & 9,336 & $-0.76^{* * *}$ \\
\hline Percent of Indication Matured Projects & 0.14 & 0.05 & 7,580 & 0.10 & 0.06 & 9,336 & $0.04 * * *$ \\
\hline
\end{tabular}




\section{Table 2. Effects of the FDAAA on Project Suspension}

The table presents results from the OLS regressions (Columns 1and 2) and the probit regressions (Columns 3 and 4). The sample consists of 16,916 project-year observations from the BioMedTracker database for our sample period from 2002 to 2012 . The dependent variable is Suspension (Indicator) that is one if the project is suspended in a given year or has no progress update for the duration longer than the 90th percentile of the sample duration with the same phase and zero otherwise. Post (Indicator) is an indicator variable that is one for project-years in the post-FDAAA period and zero for the pre-FDAAA period. The detailed descriptions of other variables are available in Appendix D. Standard errors reported in parentheses are robust and clustered by industry. ${ }^{* *}, * *$, and $*$ indicate statistical significance at the $1 \%, 5 \%$ and $10 \%$ levels, respectively.

\begin{tabular}{|c|c|c|c|c|}
\hline & \multicolumn{4}{|c|}{ Suspension (Indicator) } \\
\hline & \multicolumn{2}{|c|}{ Linear Probability Model } & \multicolumn{2}{|c|}{ Probit Model } \\
\hline & (1) & $(2)$ & (3) & (4) \\
\hline \multirow[t]{2}{*}{ Post (Indicator) } & $0.174 * * *$ & $0.126^{* * *}$ & $1.049 * * *$ & $0.627 * * *$ \\
\hline & $(0.005)$ & $(0.006)$ & $(0.039)$ & $(0.062)$ \\
\hline \multirow[t]{2}{*}{ Project with Partner (Indicator) } & & $-0.039 * * *$ & & $-0.213 * * *$ \\
\hline & & $(0.009)$ & & $(0.048)$ \\
\hline \multirow[t]{2}{*}{ Log(1+Number of Projects $)$} & & $-0.042 * * *$ & & $-0.181^{*}$ \\
\hline & & $(0.010)$ & & $(0.099)$ \\
\hline \multirow[t]{2}{*}{ Project Diversification } & & $0.075^{* *}$ & & $0.602 * * *$ \\
\hline & & $(0.034)$ & & $(0.184)$ \\
\hline \multirow[t]{2}{*}{ Percent of Matured Projects } & & -0.024 & & $-0.369 * *$ \\
\hline & & $(0.021)$ & & $(0.183)$ \\
\hline \multirow[t]{2}{*}{ Percent of Projects with Partner } & & -0.012 & & -0.116 \\
\hline & & $(0.028)$ & & $(0.179)$ \\
\hline \multirow[t]{2}{*}{ Log(1+Number of Competitors) } & & $0.096 * * *$ & & $0.811^{* * *}$ \\
\hline & & $(0.007)$ & & $(0.063)$ \\
\hline \multirow[t]{2}{*}{ Percent of Indication Matured Projects } & & 0.059 & & -0.337 \\
\hline & & $(0.035)$ & & $(0.498)$ \\
\hline Firm Fixed Effects & Yes & Yes & Yes & Yes \\
\hline Phase Fixed Effects & Yes & Yes & Yes & Yes \\
\hline Indication Fixed Effects & Yes & Yes & Yes & Yes \\
\hline Observations & 16,888 & 16,888 & 14,883 & 14,883 \\
\hline$R$-squared & 0.119 & 0.128 & & \\
\hline Adjusted $R$-squared & 0.062 & 0.072 & & \\
\hline Pseudo $R$-squared & & & 0.144 & 0.165 \\
\hline
\end{tabular}




\section{Table 3. Effects of the FDAAA on Project Suspension: Difference-in-Differences}

The table presents results from the difference-in-differences tests. The sample consists of 16,916 project-year observations from the BioMedTracker database for the sample period from 2002 to 2012. In Panel A, we divide the sample into two groups of industry-dominated (5,301 indications-year observations) and academic-dominated indications (464 indications-year observations) and compare summary statistics. Industry-dominated Indication (Indicator) is one if more than 50 percent of projects in the indication during the sample period are industry-sponsored and zero otherwise (e.g., funded by universities, hospitals, and the NIH). In Panel B, the dependent variable in Columns 1 and 2 is Suspension (Indicator) that is one if the project is suspended in a given year or has no progress update for the duration longer than the 90th percentile of the sample duration with the same phase and zero otherwise. In Columns 3 to 4, the dependent variable is the average suspension rate for each indication. Post (Indicator) is one for project-years in the post-FDAAA period and zero for the pre-FDAAA period. The detailed descriptions of other variables are available in Appendix D. Standard errors reported in parentheses are robust and clustered by industry. $* * * * *$, and $*$ indicate statistical significance at the $1 \%, 5 \%$ and $10 \%$ levels, respectively.

Panel A. Pre-FDAAA Conditions between Industry- vs. Academic-dominated Indication

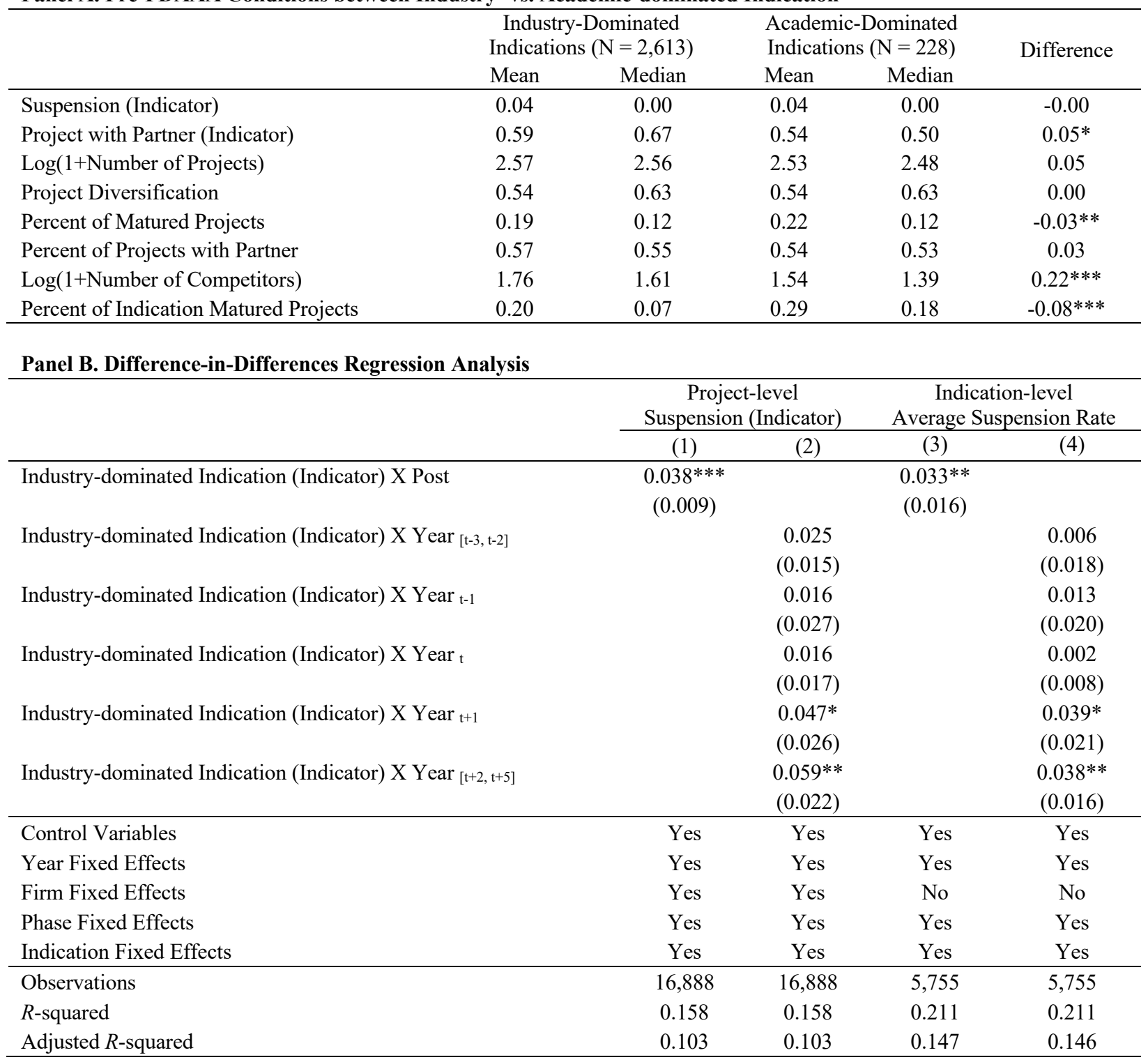




\section{Table 4. Peer Learning and Effects of FDAAA on Project Suspension}

The table presents results from the tests that examine the effects of peer disclosures on suspension decisions after the FDAAA. The sample consists of 16,916 project-year observations from the BioMedTracker database for the sample period from 2002 to 2012. The dependent variable is Suspension (Indicator) that is one if the project is suspended in a given year or has no progress update for the duration longer than the 90th percentile of the sample duration with the same phase and zero otherwise. Post (Indicator) is one for project-years in the post-FDAAA period and zero for the pre-FDAAA period. High Quality (Indicator) is one if a firm's total number of phase advances in the past three years is greater than the sample median and zero otherwise. Partner (Indicator) is one if the project has partners and zero otherwise. Peer Suspension (Lagged) is one if any peer project is suspended in the same indication as a given project's indication in the prior year. Peer Advance (Lagged) is one if any peer project advances to the next phase in the same indication as a given project's indication in the prior year. The detailed descriptions of other variables are available in Appendix D. Standard errors reported in parentheses are robust and clustered by industry. ${ }^{* * *}, * *$, and $*$ indicate statistical significance at the $1 \%, 5 \%$ and $10 \%$ levels, respectively.

\begin{tabular}{|c|c|c|c|c|c|}
\hline & & & nsion (Indic & & \\
\hline & (1) & (2) & (3) & (4) & $(5)$ \\
\hline & Full & Low & High & Without & With \\
\hline & Sample & Quality & Quality & Partner & Partner \\
\hline Peer Suspension (Lagged) X Post & $0.029 * *$ & $0.052 *$ & 0.013 & $0.042 * *$ & 0.017 \\
\hline & $(0.011)$ & $(0.030)$ & $(0.008)$ & $(0.020)$ & $(0.014)$ \\
\hline Peer Advance (Lagged) X Post & -0.004 & 0.014 & -0.019 & $-0.033 * *$ & -0.008 \\
\hline & $(0.011)$ & $(0.019)$ & $(0.014)$ & $(0.013)$ & $(0.015)$ \\
\hline Peer Suspension (Lagged) & -0.011 & $-0.042 * * *$ & 0.017 & -0.013 & 0.004 \\
\hline & $(0.008)$ & $(0.013)$ & $(0.014)$ & $(0.009)$ & $(0.011)$ \\
\hline Peer Advance (Lagged) & -0.002 & -0.002 & 0.001 & $0.032 * *$ & -0.012 \\
\hline & $(0.008)$ & $(0.014)$ & $(0.009)$ & $(0.012)$ & $(0.009)$ \\
\hline Post (Indicator) & $0.088 * * *$ & $0.092 * * *$ & $0.084 * * *$ & $0.124 * * *$ & $0.091 * * *$ \\
\hline & $(0.012)$ & $(0.027)$ & $(0.010)$ & $(0.017)$ & $(0.016)$ \\
\hline Project with Partner (Indicator) & $-0.047 * * *$ & $-0.031 *$ & $-0.057 * * *$ & & \\
\hline & $(0.011)$ & $(0.016)$ & $(0.012)$ & & \\
\hline $\log (1+$ Number of Projects $)$ & $-0.050 * * *$ & -0.022 & -0.054 & -0.049 & $-0.071 * * *$ \\
\hline & $(0.015)$ & $(0.015)$ & $(0.048)$ & $(0.030)$ & $(0.011)$ \\
\hline Project Diversification & $0.126 * * *$ & $0.088^{*}$ & $0.113^{*}$ & $0.157 * *$ & $0.137 * * *$ \\
\hline & $(0.035)$ & $(0.047)$ & $(0.057)$ & $(0.060)$ & $(0.037)$ \\
\hline Percent of Matured Projects & -0.029 & -0.062 & $-0.267 *$ & $-0.129 * *$ & -0.001 \\
\hline & $(0.026)$ & $(0.046)$ & $(0.145)$ & $(0.059)$ & $(0.058)$ \\
\hline Percent of Projects with Partner & 0.008 & 0.006 & -0.057 & $-0.106 * *$ & 0.005 \\
\hline & $(0.030)$ & $(0.047)$ & $(0.136)$ & $(0.044)$ & $(0.029)$ \\
\hline $\log (1+$ Number of Competitors $)$ & $0.130 * * *$ & $0.150 * * *$ & $0.118 * * *$ & $0.151 * * *$ & $0.145 * * *$ \\
\hline & $(0.011)$ & $(0.023)$ & $(0.009)$ & $(0.026)$ & $(0.025)$ \\
\hline Percent of Indication Matured Projects & 0.078 & $0.121^{*}$ & -0.014 & 0.090 & 0.099 \\
\hline & $(0.054)$ & $(0.066)$ & $(0.056)$ & $(0.071)$ & $(0.065)$ \\
\hline Firm Fixed Effects & Yes & Yes & Yes & Yes & Yes \\
\hline Phase Fixed Effects & Yes & Yes & Yes & Yes & Yes \\
\hline Indication Fixed Effects & Yes & Yes & Yes & Yes & Yes \\
\hline Observations & 12,763 & 6,068 & 6,329 & 5,896 & 6,841 \\
\hline$R$-squared & 0.133 & 0.194 & 0.120 & 0.168 & 0.147 \\
\hline Adjusted $R$-squared & 0.066 & 0.063 & 0.073 & 0.071 & 0.060 \\
\hline
\end{tabular}




\section{Table 5. Competition and Effects of the FDAAA on Project Suspension}

The table presents results from the tests that examine the effect of competition on suspension decisions after the FDAAA. The sample consists of 16,916 project-year observations from the BioMedTracker database for the sample period from 2002 to 2012. The dependent variable is Suspension (Indicator) that is one if the project is suspended in a given year or has no progress update for the duration longer than the 90th percentile of the sample duration with the same phase and zero otherwise. Post (Indicator) is one for project-years in the post-FDAAA period and zero for the pre-FDAAA period. High Competition (Indicator) is one if the total number of projects in the same indication as a given project's indication in a given year is greater than the sample median and zero otherwise. Non-Expedited Drugs (Indicator) is one if the project is not designated as an FDA-expedited program, including fast track, breakthrough therapy, and orphan drug, and zero otherwise. The detailed descriptions of other variables are available in Appendix D. Standard errors reported in parentheses are robust and clustered by industry. ${ }^{* * *}, * *$, and * indicate statistical significance at the $1 \%, 5 \%$ and $10 \%$ levels, respectively.

\begin{tabular}{|c|c|c|c|c|}
\hline & \multicolumn{4}{|c|}{ Suspension (Indicator) } \\
\hline & (1) & (2) & (3) & (4) \\
\hline & High & Low & Non-Expedited & Expedited \\
\hline & Competition & Competition & Drug & Drug \\
\hline \multirow[t]{2}{*}{ Post (Indicator) } & $0.110 * * *$ & $0.126^{* * *}$ & $0.139 * * *$ & $0.096 * * *$ \\
\hline & $(0.010)$ & $(0.009)$ & $(0.008)$ & $(0.012)$ \\
\hline \multirow[t]{2}{*}{ Project with Partner (Indicator) } & $-0.041 * * *$ & $-0.030 * * *$ & $-0.037 * * *$ & $-0.071 * * *$ \\
\hline & $(0.012)$ & $(0.010)$ & $(0.007)$ & $(0.019)$ \\
\hline \multirow[t]{2}{*}{ Log(1+Number of Projects $)$} & $-0.047 * * *$ & $-0.031 * *$ & $-0.043 * * *$ & $-0.058 * * *$ \\
\hline & $(0.012)$ & $(0.014)$ & $(0.010)$ & $(0.018)$ \\
\hline \multirow[t]{2}{*}{ Project Diversification } & $0.124 *$ & 0.057 & $0.087 * *$ & 0.061 \\
\hline & $(0.063)$ & $(0.035)$ & $(0.033)$ & $(0.052)$ \\
\hline \multirow[t]{2}{*}{ Percent of Matured Projects } & $-0.057 *$ & -0.025 & -0.022 & -0.055 \\
\hline & $(0.030)$ & $(0.039)$ & $(0.021)$ & $(0.054)$ \\
\hline \multirow[t]{2}{*}{ Percent of Projects with Partner } & 0.010 & -0.023 & -0.021 & -0.007 \\
\hline & $(0.037)$ & $(0.027)$ & $(0.034)$ & $(0.036)$ \\
\hline \multirow[t]{2}{*}{$\log (1+$ Number of Competitors $)$} & $0.134 * * *$ & $0.098 * * *$ & $0.100 * * *$ & $0.113 * * *$ \\
\hline & $(0.012)$ & $(0.008)$ & $(0.009)$ & $(0.014)$ \\
\hline \multirow[t]{2}{*}{ Percent of Indication Matured Projects } & $0.312 * * *$ & -0.009 & 0.070 & 0.020 \\
\hline & $(0.073)$ & $(0.039)$ & $(0.048)$ & $(0.026)$ \\
\hline Firm Fixed Effects & Yes & Yes & Yes & Yes \\
\hline Phase Fixed Effects & Yes & Yes & Yes & Yes \\
\hline Indication Fixed Effects & Yes & Yes & Yes & Yes \\
\hline Observations & 10,001 & 6,868 & 13,802 & 3,078 \\
\hline$R$-squared & 0.130 & 0.165 & 0.133 & 0.176 \\
\hline Adjusted $R$-squared & 0.082 & 0.062 & 0.073 & 0.054 \\
\hline$p$-value for different coefficients & \multicolumn{2}{|c|}{0.2166} & \multicolumn{2}{|c|}{0.0038} \\
\hline
\end{tabular}




\section{Table 6. Financial Constraints and Effects of the FDAAA on Project Suspension}

The table presents results from the tests that examine the effect of financial constraints on suspension decisions after the FDAAA. The sample consists of public firms' project-year observations from the BioMedTracker database for the sample period from 2002 to 2012. The dependent variable is Suspension (Indicator) that is one if the project is suspended in a given year or has no progress update for the duration longer than the 90th percentile of the sample duration with the same phase and zero otherwise. Post (Indicator) is one for project-years in the post-FDAAA period and zero for the pre-FDAAA period. In Columns 2 and 3 , we divide the public firm sample into subsample of firms with high and low financial constraints (KZ-index) during the preFDAAA period. The detailed descriptions of other variables are available in Appendix D. Standard errors reported in parentheses are robust and clustered by industry. $* * *, *$, and $*$ indicate statistical significance at the $1 \%, 5 \%$ and $10 \%$ levels, respectively.

\begin{tabular}{|c|c|c|c|}
\hline & $\begin{array}{c}(1) \\
\text { Full Sample }\end{array}$ & $\begin{array}{c}\text { Suspension (Indicator) } \\
\text { (2) } \\
\text { Public Sample } \\
\text { with High } \\
\text { Financial Constraint } \\
\text { (KZ-Score) } \\
\end{array}$ & $\begin{array}{c}\text { (3) } \\
\text { Public Sample } \\
\text { with Low } \\
\text { Financial Constraint } \\
\text { (KZ-Score) }\end{array}$ \\
\hline Post (Indicator) & $\begin{array}{c}0.154 * * * \\
(0.010)\end{array}$ & $\begin{array}{c}0.170 * * * \\
(0.014)\end{array}$ & $\begin{array}{c}0.131 * * * \\
(0.016)\end{array}$ \\
\hline Project with Partner (Indicator) & $\begin{array}{c}-0.030 * * * \\
(0.008)\end{array}$ & $\begin{array}{c}0.006 \\
(0.012)\end{array}$ & $\begin{array}{c}-0.057 * * * \\
(0.010)\end{array}$ \\
\hline $\log (1+$ Number of Projects $)$ & $\begin{array}{l}0.030^{*} \\
(0.015)\end{array}$ & $\begin{array}{c}0.040 \\
(0.025)\end{array}$ & $\begin{array}{l}-0.009 \\
(0.025)\end{array}$ \\
\hline Project Diversification & $\begin{array}{c}0.048 \\
(0.079)\end{array}$ & $\begin{array}{c}0.081 \\
(0.081)\end{array}$ & $\begin{array}{l}-0.198 \\
(0.117)\end{array}$ \\
\hline Percent of Matured Projects & $\begin{array}{c}0.010 \\
(0.038)\end{array}$ & $\begin{array}{l}-0.039 \\
(0.037)\end{array}$ & $\begin{array}{c}0.041 \\
(0.069)\end{array}$ \\
\hline Percent of Projects with Partner & $\begin{array}{c}0.086 \\
(0.068)\end{array}$ & $\begin{array}{c}0.069 \\
(0.097)\end{array}$ & $\begin{array}{c}0.076 \\
(0.077)\end{array}$ \\
\hline $\log (1+$ Number of Competitors $)$ & $\begin{array}{c}0.073 * * * \\
(0.010)\end{array}$ & $\begin{array}{c}0.060 * * * \\
(0.015)\end{array}$ & $\begin{array}{c}0.124 * * * \\
(0.023)\end{array}$ \\
\hline Percent of Indication Matured Projects & $\begin{array}{l}-0.007 \\
(0.020)\end{array}$ & $\begin{array}{c}0.045 \\
(0.036)\end{array}$ & $\begin{array}{c}-0.091 * * * \\
(0.023)\end{array}$ \\
\hline Firm Size & $\begin{array}{l}-0.012 * \\
(0.006)\end{array}$ & $\begin{array}{c}-0.022 * * * \\
(0.007)\end{array}$ & $\begin{array}{l}0.073 * \\
(0.037)\end{array}$ \\
\hline R\&D Expense/Assets & $\begin{array}{c}-0.012 * * * \\
(0.003)\end{array}$ & $\begin{array}{c}-0.013^{* * *} \\
(0.004)\end{array}$ & $\begin{array}{c}0.015 \\
(0.012)\end{array}$ \\
\hline $\mathrm{KZ}$ index & $\begin{array}{c}0.001 * * * \\
(0.000)\end{array}$ & & \\
\hline Firm Fixed Effects & Yes & Yes & Yes \\
\hline Phase Fixed Effects & Yes & Yes & Yes \\
\hline Indication Fixed Effects & Yes & Yes & Yes \\
\hline Observations & 5154 & 3134 & 2065 \\
\hline$R$-squared & 0.170 & 0.197 & 0.183 \\
\hline Adjusted $R$-squared & 0.105 & 0.112 & 0.109 \\
\hline$p$-value for different coefficients & & & 0.1198 \\
\hline
\end{tabular}




\section{Table 7. Public Status and Effects of the FDAAA on Project Suspension}

This table presents results from the tests that examine the effects of public status on suspension decisions after the FDAAA. The sample consists of 16,916 project-year observations from the BioMedTracker database for the sample period from 2002 to 2012. The dependent variable is Suspension (Indicator) that is one if the project is suspended in a given year or has no progress update for the duration longer than the 90th percentile of the sample duration with the same phase and zero otherwise. Post (Indicator) is one for project-years in the post-FDAAA period and zero for the pre-FDAAA period. We consider subsamples of projects that are sponsored by publicly-listed companies in Columns 1 and 2 and by private companies in Columns 3 to 4 . Firms that go public eventually during our sample period are considered as public firms. Thus, part of their observations do not have Compustat data. The detailed descriptions of other variables are available in Appendix D. Standard errors reported in parentheses are robust and clustered by industry. ${ }^{* * *}, * *$, and $*$ indicate statistical significance at the $1 \%, 5 \%$ and $10 \%$ levels, respectively.

\begin{tabular}{|c|c|c|c|c|}
\hline & \multicolumn{4}{|c|}{ Suspension (Indicator) } \\
\hline & (1) & (2) & (3) & (4) \\
\hline & Public Sample & Public Sample & Private Sample & Private Sample \\
\hline \multirow[t]{2}{*}{ Post (Indicator) } & $0.126^{* * *}$ & $0.119 * * *$ & $0.105 * * *$ & $0.104 * * *$ \\
\hline & $(0.006)$ & $(0.006)$ & $(0.011)$ & $(0.010)$ \\
\hline \multirow[t]{2}{*}{ Project with Partner (Indicator) } & $-0.044 * * *$ & $-0.042 * * *$ & -0.021 & -0.021 \\
\hline & $(0.009)$ & $(0.012)$ & $(0.014)$ & $(0.014)$ \\
\hline \multirow[t]{2}{*}{ Log(1+Number of Projects $)$} & $-0.037 * *$ & -0.017 & $-0.054 * * *$ & $-0.054 * * *$ \\
\hline & $(0.017)$ & $(0.015)$ & $(0.015)$ & $(0.015)$ \\
\hline \multirow[t]{2}{*}{ Project Diversification } & 0.010 & -0.033 & $0.173 * * *$ & $0.171 * * *$ \\
\hline & $(0.056)$ & $(0.095)$ & $(0.037)$ & $(0.038)$ \\
\hline \multirow[t]{2}{*}{ Percent of Matured Projects } & -0.045 & 0.018 & -0.025 & -0.025 \\
\hline & $(0.033)$ & $(0.034)$ & $(0.030)$ & $(0.030)$ \\
\hline \multirow[t]{2}{*}{ Percent of Projects with Partner } & -0.008 & -0.062 & $-0.049 *$ & $-0.048^{*}$ \\
\hline & $(0.036)$ & $(0.083)$ & $(0.024)$ & $(0.024)$ \\
\hline \multirow[t]{2}{*}{ Log(1+Number of Competitors) } & $0.098 * * *$ & $0.085 * * *$ & $0.112 * * *$ & $0.111 * * *$ \\
\hline & $(0.007)$ & $(0.011)$ & $(0.019)$ & $(0.019)$ \\
\hline \multirow[t]{2}{*}{ Percent of Indication Matured Projects } & 0.040 & 0.006 & $0.065^{*}$ & $0.064 *$ \\
\hline & $(0.040)$ & $(0.023)$ & $(0.031)$ & $(0.031)$ \\
\hline \multirow[t]{2}{*}{ Firm Size } & & 0.000 & & \\
\hline & & $(0.007)$ & & \\
\hline \multirow[t]{2}{*}{ R\&D Expense/Assets } & & -0.002 & & \\
\hline & & $(0.004)$ & & \\
\hline \multirow[t]{2}{*}{ Log(1+Total VC Funding) } & & & & 0.012 \\
\hline & & & & $(0.015)$ \\
\hline Firm Fixed Effects & Yes & Yes & Yes & Yes \\
\hline Phase Fixed Effects & Yes & Yes & Yes & Yes \\
\hline Indication Fixed Effects & Yes & Yes & Yes & Yes \\
\hline Observations & 12,565 & 7,561 & 4,268 & 4,268 \\
\hline$R$-squared & 0.127 & 0.128 & 0.190 & 0.190 \\
\hline Adjusted $R$-squared & 0.073 & 0.071 & 0.061 & 0.061 \\
\hline$p$-value for different coefficients in (1) and (3) & & & & \\
\hline
\end{tabular}




\section{Table 8. Effects of the FDAAA on Drug Quality: Adverse Event Reports (AER)}

The table presents results from the tests that examine the effects of the FDAAA on drug quality using adverse event reports from the FDA Adverse Event Reporting System (AERS) data for the drugs in our sample for the period from 2004 to 2012 . The AERS data start in 2004. We restrict our sample to marketed drugs that are approved by the FDA in and after 1990. In Columns 1 and $2, \log (1+$ Number of AER) is the log of one plus the total number of adverse event reports (AER) for the drug in a given year in which the drug is reported as primary suspect. In Columns 3 and $4, \log (1+$ Number of Serious AER) is the log of one plus the total number of AER in which the patient outcome is one of the serious conditions (death, life-threatening, hospitalization, disability, congenital anomaly, or required intervention to prevent permanent impairment and damage), and the drug is reported as a primary suspect. Project Initiation After FDAAA (Indicator) is an indicator variable that is one if the project is initiated after the passage of FDAAA in 2007 and zero otherwise. The detailed descriptions of other variables are available in Appendix D. Standard errors reported in parentheses are robust and clustered by industry. ***, **, and * indicate statistical significance at the $1 \%, 5 \%$ and $10 \%$ levels, respectively.

\begin{tabular}{|c|c|c|c|c|}
\hline & \multicolumn{2}{|c|}{$\log (1+$ Number of AER $)$} & \multicolumn{2}{|c|}{$\log (1+$ Number of Serious AER $)$} \\
\hline & $(1)$ & $(2)$ & (3) & (4) \\
\hline \multirow[t]{2}{*}{ Project Initiation After FDAAA } & $-1.059 * * *$ & $-0.830 * * *$ & $-1.016 * * *$ & $-0.798 * * *$ \\
\hline & $(0.231)$ & $(0.211)$ & $(0.217)$ & $(0.204)$ \\
\hline \multirow[t]{2}{*}{ Years from Approval } & $-0.065 * * *$ & $-0.094 * *$ & $-0.059 * * *$ & $-0.089 * *$ \\
\hline & $(0.020)$ & $(0.037)$ & $(0.018)$ & $(0.033)$ \\
\hline \multirow[t]{2}{*}{ Project with Partner (Indicator) } & & $0.678 * * *$ & & $0.680 * * *$ \\
\hline & & $(0.171)$ & & $(0.167)$ \\
\hline \multirow[t]{2}{*}{ Project Diversification } & & 0.419 & & 0.408 \\
\hline & & $(0.459)$ & & $(0.406)$ \\
\hline \multirow[t]{2}{*}{ Log(1+Number of Projects $)$} & & $-0.545^{* * *}$ & & $-0.506^{* * *}$ \\
\hline & & $(0.168)$ & & $(0.171)$ \\
\hline \multirow[t]{2}{*}{ Percent of Matured Projects } & & -0.696 & & -0.575 \\
\hline & & $(0.508)$ & & $(0.449)$ \\
\hline \multirow[t]{2}{*}{ Percent of Projects with Partner } & & -0.065 & & -0.126 \\
\hline & & $(0.498)$ & & $(0.453)$ \\
\hline \multirow[t]{2}{*}{ Log(1+Number of Competitors) } & & 0.180 & & 0.159 \\
\hline & & $(0.156)$ & & $(0.152)$ \\
\hline \multirow[t]{2}{*}{ Percent of Indication Matured Projects } & & 0.178 & & 0.137 \\
\hline & & $(0.415)$ & & $(0.417)$ \\
\hline Firm Fixed Effects & Yes & Yes & Yes & Yes \\
\hline Indication Fixed Effects & Yes & Yes & Yes & Yes \\
\hline Year Fixed Effects & Yes & Yes & Yes & Yes \\
\hline Observations & 6,833 & 6,833 & 6,833 & 6,833 \\
\hline$R$-squared & 0.553 & 0.570 & 0.557 & 0.573 \\
\hline Adjusted $R$-squared & 0.527 & 0.543 & 0.531 & 0.547 \\
\hline
\end{tabular}




\section{Table 9. Likelihood of Delivering AER}

The table presents results from the linear probability model regressions that examine the likelihood of receiving an adverse event report. We use adverse event reports from the FDA Adverse Event Reporting System (AERS) data for the drugs in our sample for the period from 2004 to 2012. The AERS data start in 2004. We restrict our sample to marketed drugs that are approved by the FDA in and after 1990. In Columns 1 to 2, the dependent variable is Primary Suspect in AER (Indicator) that is one if the drug is a primary suspect in any AER in a given year and zero otherwise. In Columns 3 to 4, the dependent variable is Primary Suspect in Serious AER (Indicator) that is one if the drug is a primary suspect in an AER with serious patient outcomes in a given year and zero otherwise. Project Initiation After FDAAA (Indicator) is an indicator variable is one if the drug project is initiated after the passage of FDAAA in 2007 and zero otherwise. The detailed descriptions of other variables are available in Appendix D. Standard errors reported in parentheses are robust and clustered by industry. ***, **, and * indicate statistical significance at the $1 \%, 5 \%$ and $10 \%$ levels, respectively.

\begin{tabular}{|c|c|c|c|c|}
\hline & \multicolumn{2}{|c|}{ Primary Suspect in AER } & \multicolumn{2}{|c|}{ Primary Suspect in Serious AER } \\
\hline & (1) & (2) & (3) & (4) \\
\hline \multirow[t]{2}{*}{ Project Initiation After FDAAA } & $-0.066^{* *}$ & $-0.049 *$ & $-0.113^{* *}$ & $-0.092 * *$ \\
\hline & $(0.029)$ & $(0.027)$ & $(0.040)$ & $(0.039)$ \\
\hline \multirow[t]{2}{*}{ Years from Approval } & $-0.008 * * *$ & $-0.013 * * *$ & $-0.009 * * *$ & $-0.014 * * *$ \\
\hline & $(0.003)$ & $(0.004)$ & $(0.003)$ & $(0.004)$ \\
\hline \multirow[t]{2}{*}{ Project with Partner (Indicator) } & & $0.021 *$ & & $0.032 *$ \\
\hline & & $(0.012)$ & & $(0.016)$ \\
\hline \multirow[t]{2}{*}{ Project Diversification } & & 0.089 & & $0.105^{*}$ \\
\hline & & $(0.058)$ & & $(0.055)$ \\
\hline \multirow[t]{2}{*}{ Log(1+Number of Projects) } & & $-0.056 * * *$ & & $-0.063^{* * *}$ \\
\hline & & $(0.013)$ & & $(0.017)$ \\
\hline \multirow[t]{2}{*}{ Percent of Matured Projects } & & -0.018 & & -0.016 \\
\hline & & $(0.057)$ & & $(0.058)$ \\
\hline \multirow[t]{2}{*}{ Percent of Projects with Partner } & & 0.008 & & 0.012 \\
\hline & & $(0.051)$ & & $(0.054)$ \\
\hline \multirow[t]{2}{*}{ Log(1+Number of Competitors) } & & 0.021 & & $0.031 *$ \\
\hline & & $(0.015)$ & & $(0.017)$ \\
\hline \multirow[t]{2}{*}{ Percent of Indication Matured Projects } & & 0.008 & & 0.033 \\
\hline & & $(0.025)$ & & $(0.034)$ \\
\hline Firm Fixed Effects & Yes & Yes & Yes & Yes \\
\hline Indication Fixed Effects & Yes & Yes & Yes & Yes \\
\hline Year Fixed Effects & Yes & Yes & Yes & Yes \\
\hline Observations & 6,833 & 6,833 & 6,833 & 6,833 \\
\hline$R$-squared & 0.353 & 0.360 & 0.374 & 0.381 \\
\hline Adjusted $R$-squared & 0.314 & 0.321 & 0.336 & 0.343 \\
\hline
\end{tabular}




\section{Table 10: Disability-Adjusted-Life-Years (DALY) by Active Project Growth}

The table examines how the changes in project growth rates and suspension rates before and after the FDAAA are associated with the changes in DALY at the indication level. We use the two points DALY data from the WHO for 2000 and 2016 . We split indications into the two groups with (a) low and (b) high project growth before and after the FDAAA. The significance in Column Difference (a)-(b) is based on $t$-statistics from the $t$-tests for the equality of means in the two groups. Panel A shows the differences in average growth rates and suspension rates between the pre- and the post-FDAAA periods. In Panel B, we quantify the changes in the Burden of Disease based on DALY for each indication. DALY (million years) are the years lived with disability and the years of life lost due to that disease in millions. DALY (\%) represents the fraction of DALY (years) attributable to a given disease in DALY (years) for any disease. $* * *, * *$, and $*$ indicate statistical significance at the $1 \%, 5 \%$ and $10 \%$ levels, respectively.

Panel A. Changes in Project Growth Rates and Suspension Rates

\begin{tabular}{lcccc}
\hline & $\begin{array}{c}\text { (a) Indications with } \\
\text { low project growth }\end{array}$ & $\begin{array}{c}\text { (b) Indications with } \\
\text { high project growth }\end{array}$ & Difference (a)-(b) $t$-stat \\
\hline Difference, Post - Pre: & & & & \\
(1) Active projects growth rates & -0.462 & 0.049 & $-0.511^{* * *}$ & -11.74 \\
(2) Suspension rates & 0.070 & 0.031 & $0.038^{* *}$ & 2.39 \\
Observations & 69 & 66 & 135 & \\
\hline
\end{tabular}

Panel B. Changes in the Burden of Disease Based on DALY

\begin{tabular}{|c|c|c|c|c|}
\hline & $\begin{array}{l}\text { (a) Indications with } \\
\text { low project growth }\end{array}$ & $\begin{array}{l}\text { (b) Indications with } \\
\text { high project growth }\end{array}$ & Difference (a)-(b) & $t$-stat \\
\hline \multicolumn{5}{|l|}{ Pre-FDAAA period, 2000: } \\
\hline (1) DALY (million years) & 91.900 & 100.542 & -8.643 & -0.76 \\
\hline (2) DALY (\%) & $3.26 \%$ & $3.57 \%$ & $-0.31 \%$ & -0.76 \\
\hline \multicolumn{5}{|l|}{ Difference, 2016 - 2000: } \\
\hline (3) DALY (million years) & -2.800 & -21.483 & $18.683 * *$ & 2.60 \\
\hline (4) DALY (\%) & $0.08 \%$ & $-0.59 \%$ & $0.67 \% * * *$ & 2.63 \\
\hline \multicolumn{5}{|l|}{ Percentage Change: } \\
\hline (5) (2016 DALY - 2000 DALY) / 2000 DALY & $4.21 \%$ & $-8.27 \%$ & $12.48 \% * *$ & 2.08 \\
\hline Observations & 69 & 66 & 135 & \\
\hline
\end{tabular}




\section{Internet Appendix for}

"Enhanced Information Disclosure and Drug Development: Evidence from Mandatory Reporting of Clinical Trials" 


\section{Table A.1 Effects of the FDAAA on Disclosed Project Suspension}

The table presents results from the OLS regressions (Columns 1and 2) and the probit regressions (Columns 3 and 4). The sample consists of 16,916 project-year observations from the BioMedTracker database for our sample period from 2002 to 2012 . The dependent variable is Disclosed Suspension (Indicator) that is one if a suspension announcement is made for the project in a given year and zero otherwise. Post (Indicator) is an indicator variable that is one for project-years in the post-FDAAA period and zero for the pre-FDAAA period. The detailed descriptions of other variables are available in Appendix D. Standard errors reported in parentheses are robust and clustered by industry. $* * * * *$, and $*$ indicate statistical significance at the $1 \%, 5 \%$ and $10 \%$ levels, respectively.

Disclosed Suspension (Indicator)

\begin{tabular}{|c|c|c|c|c|}
\hline & \multicolumn{4}{|c|}{ Disclosed Suspension (Indicator) } \\
\hline & \multicolumn{2}{|c|}{ Linear Probability Model } & \multicolumn{2}{|c|}{ Probit Model } \\
\hline & (1) & (2) & (3) & (4) \\
\hline \multirow[t]{2}{*}{ Post (Indicator) } & $0.127 * * *$ & $0.097 * * *$ & $0.914 * * *$ & $0.614 * * *$ \\
\hline & $(0.006)$ & $(0.006)$ & $(0.027)$ & $(0.051)$ \\
\hline \multirow[t]{2}{*}{ Project with Partner (Indicator) } & & $-0.046 * * *$ & & $-0.277 * * *$ \\
\hline & & $(0.008)$ & & $(0.042)$ \\
\hline \multirow[t]{2}{*}{$\log (1+$ Number of Projects $)$} & & 0.003 & & 0.025 \\
\hline & & $(0.007)$ & & $(0.098)$ \\
\hline \multirow[t]{2}{*}{ Project Diversification } & & 0.035 & & $0.603 * *$ \\
\hline & & $(0.042)$ & & $(0.307)$ \\
\hline \multirow[t]{2}{*}{ Percent of Matured Projects } & & -0.015 & & -0.276 \\
\hline & & $(0.016)$ & & $(0.175)$ \\
\hline \multirow[t]{2}{*}{ Percent of Projects with Partner } & & 0.031 & & 0.181 \\
\hline & & $(0.030)$ & & $(0.229)$ \\
\hline \multirow[t]{2}{*}{$\log (1+$ Number of Competitors $)$} & & $0.041 * * *$ & & $0.452 * * *$ \\
\hline & & $(0.005)$ & & $(0.063)$ \\
\hline \multirow[t]{2}{*}{ Percent of Indication Matured Projects } & & $0.044 *$ & & -0.282 \\
\hline & & $(0.023)$ & & $(0.450)$ \\
\hline Firm Fixed Effects & Yes & Yes & Yes & Yes \\
\hline Phase Fixed Effects & Yes & Yes & Yes & Yes \\
\hline Indication Fixed Effects & Yes & Yes & Yes & Yes \\
\hline Observations & 16,888 & 16,888 & 13,268 & 13,268 \\
\hline$R$-squared & 0.120 & 0.126 & & \\
\hline Adjusted $R$-squared & 0.064 & 0.069 & & \\
\hline Pseudo $R$-squared & & & 0.145 & 0.158 \\
\hline
\end{tabular}

IA p.1 


\section{Table A.2. Effects of the FDAAA on Project Suspension: Financial Crisis}

The table presents results from the tests that examine the effects of the FDAAA on suspension decisions after excluding the financial crisis period. Considering the financial crisis neighboring the enactment of the FDAAA in 2007, we use a refined sample that excludes observations in the two-year event window, $[-2,+2]$, surrounding 2007 (i.e., five year observations in 2005 , 2006, 2007, 2008, and 2009) in Columns 1 and 2, or that excludes observations in 2008 and 2009 in Columns 3 and 4 . The dependent variable is Suspension (Indicator) that is one if the project is suspended in a given year or has no progress update for the duration longer than the 90th percentile of the sample duration with the same phase and zero otherwise. Post (Indicator) is one for project-years in the post-FDAAA period and zero for the pre-FDAAA period. The detailed descriptions of other variables are available in Appendix D. Standard errors reported in parentheses are robust and clustered by industry. $* * *$, **, and * indicate statistical significance at the $1 \%, 5 \%$ and $10 \%$ levels, respectively.

\begin{tabular}{|c|c|c|c|c|}
\hline & \multicolumn{4}{|c|}{ Suspension (Indicator) } \\
\hline & \multicolumn{2}{|c|}{$\begin{array}{l}\text { Excluding Financial Crisis } \\
\text { Window }[-2,+2]\end{array}$} & \multicolumn{2}{|c|}{$\begin{array}{c}\text { Excluding Financial } \\
\text { Crisis Period 2008-2009 }\end{array}$} \\
\hline & (1) & (2) & (3) & (4) \\
\hline \multirow[t]{2}{*}{ Post (Indicator) } & $0.228 * * *$ & $0.178 * * *$ & $0.224 * * *$ & $0.194 * * *$ \\
\hline & $(0.012)$ & $(0.027)$ & $(0.008)$ & $(0.011)$ \\
\hline \multirow[t]{2}{*}{ Project with Partner (Indicator) } & & $-0.055 * * *$ & & $-0.038 * * *$ \\
\hline & & $(0.008)$ & & $(0.004)$ \\
\hline \multirow[t]{2}{*}{$\log (1+$ Number of Projects $)$} & & $-0.053 * * *$ & & $-0.036^{* * *}$ \\
\hline & & $(0.010)$ & & $(0.007)$ \\
\hline \multirow[t]{2}{*}{ Project Diversification } & & 0.038 & & $0.047 * *$ \\
\hline & & $(0.026)$ & & $(0.022)$ \\
\hline \multirow[t]{2}{*}{ Percent of Matured Projects } & & $-0.062 * *$ & & $-0.044 * *$ \\
\hline & & $(0.026)$ & & $(0.020)$ \\
\hline \multirow[t]{2}{*}{ Percent of Projects with Partner } & & -0.009 & & -0.020 \\
\hline & & $(0.029)$ & & $(0.028)$ \\
\hline \multirow[t]{2}{*}{$\log (1+$ Number of Competitors $)$} & & $0.078 * * *$ & & $0.056 * * *$ \\
\hline & & $(0.010)$ & & $(0.005)$ \\
\hline \multirow[t]{2}{*}{ Percent of Indication Matured Projects } & & 0.066 & & 0.026 \\
\hline & & $(0.047)$ & & $(0.030)$ \\
\hline Firm Fixed Effects & Yes & Yes & Yes & Yes \\
\hline Phase Fixed Effects & Yes & Yes & Yes & Yes \\
\hline Indication Fixed Effects & Yes & Yes & Yes & Yes \\
\hline Observations & 7,520 & 7,520 & 12,106 & 12,106 \\
\hline$R$-squared & 0.208 & 0.216 & 0.175 & 0.180 \\
\hline Adjusted $R$-squared & 0.095 & 0.102 & 0.100 & 0.105 \\
\hline
\end{tabular}




\section{Table A.3. Effects of the FDAAA on New Project Initiation}

The table presents results from the tests that examine the effects of the FDAAA on new project initiation decisions. In Columns 1 and 2 , the dependent variable is the log of one plus the total number of new projects initiated by the firm in a given year. In Columns 3 and 4, the dependent variable is the log of one plus the total number of new projects in each indication by the firm in a given year. Post (Indicator) is one for project-years in the post-FDAAA period and zero for the pre-FDAAA period. The detailed descriptions of other variables are available in Appendix D. Standard errors reported in parentheses are robust and clustered by industry. $* * * * *$, and $*$ indicate statistical significance at the $1 \%, 5 \%$ and $10 \%$ levels, respectively.

\begin{tabular}{|c|c|c|c|c|}
\hline & \multicolumn{4}{|c|}{$\log (1+$ Number of New Initiated Projects $)$} \\
\hline & \multicolumn{2}{|c|}{ Firm-Year level } & \multicolumn{2}{|c|}{ Firm-Indication-Year level } \\
\hline & (1) & $(2)$ & $(3)$ & (4) \\
\hline \multirow[t]{2}{*}{ Post (Indicator) } & $-0.200 * * *$ & $-0.184 * * *$ & $-0.207 * * *$ & $-0.196 * * *$ \\
\hline & $(0.008)$ & $(0.013)$ & $(0.004)$ & $(0.009)$ \\
\hline \multirow[t]{2}{*}{ Project with Partner } & & -0.012 & & $-0.025 * * *$ \\
\hline & & $(0.041)$ & & $(0.006)$ \\
\hline \multirow[t]{2}{*}{$\log (1+$ Number of Projects $)$} & & $0.072 * * *$ & & $0.036 * *$ \\
\hline & & $(0.022)$ & & $(0.016)$ \\
\hline \multirow[t]{2}{*}{ Project Diversification } & & $-0.088 * * *$ & & $-0.163 * * *$ \\
\hline & & $(0.028)$ & & $(0.029)$ \\
\hline \multirow[t]{2}{*}{ Percent of Matured Projects } & & -0.031 & & -0.021 \\
\hline & & $(0.040)$ & & $(0.032)$ \\
\hline \multirow[t]{2}{*}{ Percent of Projects with Partner } & & 0.024 & & 0.020 \\
\hline & & $(0.028)$ & & $(0.019)$ \\
\hline \multirow[t]{2}{*}{$\log (1+$ Number of Competitors $)$} & & $-0.050 * * *$ & & $-0.037 * * *$ \\
\hline & & $(0.006)$ & & $(0.008)$ \\
\hline \multirow[t]{2}{*}{ Percent of Indication Matured Projects } & & $0.105 * *$ & & -0.025 \\
\hline & & $(0.042)$ & & $(0.021)$ \\
\hline Firm Fixed Effects & Yes & Yes & Yes & Yes \\
\hline Indication Fixed Effects & No & No & Yes & Yes \\
\hline Observations & 4,275 & 4,275 & 14,636 & 14,636 \\
\hline$R$-squared & 0.301 & 0.314 & 0.199 & 0.204 \\
\hline Adjusted $R$-squared & 0.183 & 0.197 & 0.139 & 0.144 \\
\hline
\end{tabular}


Table A.4. List of Academic-Dominated Indications

The table presents the list of top 30 academic-dominated indications. Academic-dominated indications are the ones with more than 50 percent of projects are funded by non-industry sponsors (e.g., universities, hospitals, and the NIH).

\begin{tabular}{|c|c|c|c|c|}
\hline Indication & $\begin{array}{c}\text { Ratio of } \\
\text { Academic- } \\
\text { sponsored } \\
\text { Projects }\end{array}$ & $\begin{array}{l}\text { Number of } \\
\text { Industry- } \\
\text { sponsored } \\
\text { Projects }\end{array}$ & $\begin{array}{c}\text { Number of } \\
\text { Academic- } \\
\text { sponsored } \\
\text { Projects }\end{array}$ & $\begin{array}{c}\text { Total Number } \\
\text { of Drug } \\
\text { Projects }\end{array}$ \\
\hline Cancer & $96 \%$ & 5 & 137 & 142 \\
\hline Metabolic-General & $90 \%$ & 2 & 19 & 21 \\
\hline Transplant Rejection & $89 \%$ & 2 & 16 & 18 \\
\hline Alcohol Dependence & $80 \%$ & 9 & 35 & 44 \\
\hline Esophageal Cancer & $78 \%$ & 7 & 25 & 32 \\
\hline End-Stage Renal Disease (ESRD) & $76 \%$ & 4 & 13 & 17 \\
\hline Urinary Incontinence & $75 \%$ & 1 & 3 & 4 \\
\hline Respiratory Distress Syndrome (RDS) & $75 \%$ & 2 & 6 & 8 \\
\hline Aplastic Anemia & $75 \%$ & 1 & 3 & 4 \\
\hline Myopic Macular Degeneration (MMD) & $75 \%$ & 2 & 6 & 8 \\
\hline Endometrial Hyperplasia & $75 \%$ & 1 & 3 & 4 \\
\hline Acute Promyelocytic Leukemia (APL) & $75 \%$ & 1 & 3 & 4 \\
\hline Coronary Artery Disease & $74 \%$ & 13 & 37 & 50 \\
\hline Fever & $71 \%$ & 2 & 5 & 7 \\
\hline Mild Cognitive Impairment (MCI) & $71 \%$ & 2 & 5 & 7 \\
\hline Cardiovascular Disease & $71 \%$ & 6 & 15 & 21 \\
\hline Preterm Labor & $70 \%$ & 3 & 7 & 10 \\
\hline Malaria & $68 \%$ & 12 & 26 & 38 \\
\hline Nasal Polyposis & $67 \%$ & 1 & 2 & 3 \\
\hline Vitiligo & $67 \%$ & 1 & 2 & 3 \\
\hline Turner Syndrome & $67 \%$ & 1 & 2 & 3 \\
\hline Panic Disorder & $67 \%$ & 2 & 4 & 6 \\
\hline Chronic Cough & $67 \%$ & 3 & 6 & 9 \\
\hline HIV / AIDS & $66 \%$ & 57 & 110 & 167 \\
\hline Traumatic Brain Injury (TBI) & $64 \%$ & 5 & 9 & 14 \\
\hline Liver Transplant Rejection & $61 \%$ & 7 & 11 & 18 \\
\hline Hepatitis B (HBV) Treatment (Antiviral) & $61 \%$ & 15 & 23 & 38 \\
\hline Allergy & $60 \%$ & 2 & 3 & 5 \\
\hline Smoking Cessation & $59 \%$ & 11 & 16 & 27 \\
\hline Anesthesia & $59 \%$ & 7 & 10 & 17 \\
\hline
\end{tabular}




\section{Table A.5. Effects of the FDAAA on Project Suspension: Excluding M\&A}

The table presents results from the tests that examine the effects of the FDAAA on project suspension decision after excluding firms that experience any M\&A transactions (either as acquirers or targets) in the past three years. We show the results from the OLS regressions in Columns 1 and 2 and the result from the difference-in-differences test in Column 3 . The sample consists of 10,505 project-year observations from the BioMedTracker database for our sample period from 2002 to 2012. The dependent variable is Suspension (Indicator) that is one if the project is suspended in a given year or has no progress update for the duration longer than the 90th percentile of the sample duration with the same phase and zero otherwise. Post (Indicator) is one for projectyears in the post-FDAAA period and zero for the pre-FDAAA period. The detailed descriptions of other variables are available in Appendix D. Standard errors reported in parentheses are robust and clustered by industry. ***, **, and * indicate statistical significance at the $1 \%, 5 \%$ and $10 \%$ levels, respectively.

\begin{tabular}{|c|c|c|c|}
\hline & \multicolumn{3}{|c|}{ Suspension (Indicator) } \\
\hline & $(1)$ & $(2)$ & (3) \\
\hline \multirow[t]{2}{*}{ Post (Indicator) } & $0.186^{* * *}$ & $0.130 * * *$ & \\
\hline & $(0.008)$ & $(0.007)$ & \\
\hline \multirow[t]{2}{*}{ Post (Indicator) X Industry-dominated Indication (Indicator) } & & & $0.036^{*}$ \\
\hline & & & $(0.018)$ \\
\hline \multirow[t]{2}{*}{ Project with Partner (Indicator) } & & $-0.036 * *$ & $-0.036 * * *$ \\
\hline & & $(0.013)$ & $(0.012)$ \\
\hline \multirow[t]{2}{*}{ Log(1+Number of Projects $)$} & & $-0.029 * *$ & -0.008 \\
\hline & & $(0.012)$ & $(0.014)$ \\
\hline \multirow[t]{2}{*}{ Project Diversification } & & 0.050 & 0.027 \\
\hline & & $(0.035)$ & $(0.045)$ \\
\hline \multirow[t]{2}{*}{ Percent of Matured Projects } & & $-0.042 * *$ & $-0.059 * * *$ \\
\hline & & $(0.017)$ & $(0.015)$ \\
\hline \multirow[t]{2}{*}{ Percent of Projects with Partner } & & -0.026 & 0.006 \\
\hline & & $(0.025)$ & $(0.023)$ \\
\hline \multirow[t]{2}{*}{$\log (1+$ Number of Competitors $)$} & & $0.098 * * *$ & $0.030 * *$ \\
\hline & & $(0.012)$ & $(0.014)$ \\
\hline \multirow[t]{2}{*}{ Percent of Indication Matured Projects } & & $0.081 * *$ & 0.027 \\
\hline & & $(0.030)$ & $(0.022)$ \\
\hline Year Fixed Effects & No & No & Yes \\
\hline Firm and Institution Fixed Effects & Yes & Yes & Yes \\
\hline Phase Fixed Effects & Yes & Yes & Yes \\
\hline Indication Fixed Effects & Yes & Yes & Yes \\
\hline Observations & 10,505 & 10,505 & 10,505 \\
\hline$R$-squared & 0.150 & 0.160 & 0.201 \\
\hline Adjusted $R$-squared & 0.063 & 0.074 & 0.118 \\
\hline
\end{tabular}




\section{Table A.6. Effects of the FDAAA on Project Suspension: Including Projects in All Phases}

and Initiated After FDAAA

The table presents results from the tests that examine the effects of the FDAAA on project suspension decisions after including Phase 1 projects and projects that are initiated after the FDAAA. We show the results from the OLS regressions in Columns 1 and 2 and the result from the difference-in-differences test in Column 3. The sample consists of 23,159 project-year observations from the BioMedTracker database for our sample period from 2002 to 2012. The dependent variable is Suspension (Indicator) that is one if the project is suspended in a given year or has no progress update for the duration longer than the 90th percentile of the sample duration with the same phase and zero otherwise. Post (Indicator) is one for project-years in the post-FDAAA period and zero for the pre-FDAAA period. The detailed descriptions of other variables are available in Appendix D. Standard errors reported in parentheses are robust and clustered by industry. $* * *, *$, and * indicate statistical significance at the $1 \%, 5 \%$ and $10 \%$ levels, respectively.

\begin{tabular}{|c|c|c|c|}
\hline & \multicolumn{3}{|c|}{ Suspension (Indicator) } \\
\hline & (1) & $(2)$ & (3) \\
\hline Post (Indicator) & $\begin{array}{c}0.169 * * * \\
(0.005)\end{array}$ & $\begin{array}{c}0.121 * * * \\
(0.005)\end{array}$ & \\
\hline Post (Indicator) X Industry-dominated Indication (Indicator) & & & $\begin{array}{c}0.078 * * * \\
(0.012)\end{array}$ \\
\hline Project with Partner (Indicator) & & $\begin{array}{c}-0.036 * * * \\
(0.006)\end{array}$ & $\begin{array}{c}-0.040 * * * * \\
(0.006)\end{array}$ \\
\hline Log(1+Number of Projects $)$ & & $\begin{array}{c}-0.032 * * * \\
(0.008)\end{array}$ & $\begin{array}{c}-0.029 * * * * \\
(0.005)\end{array}$ \\
\hline Project Diversification & & $\begin{array}{c}0.029 \\
(0.031)\end{array}$ & $\begin{array}{c}0.013 \\
(0.031)\end{array}$ \\
\hline Percent of Matured Projects & & $\begin{array}{c}-0.034^{*} \\
(0.017)\end{array}$ & $\begin{array}{c}-0.039 \\
(0.024)\end{array}$ \\
\hline Percent of Projects with Partner & & $\begin{array}{l}-0.025 \\
(0.018)\end{array}$ & $\begin{array}{l}-0.012 \\
(0.020)\end{array}$ \\
\hline $\log (1+$ Number of Competitors $)$ & & $\begin{array}{c}0.089 * * * \\
(0.007)\end{array}$ & $\begin{array}{c}0.024 * * * \\
(0.007)\end{array}$ \\
\hline Percent of Indication Matured Projects & & $\begin{array}{c}0.055^{* *} \\
(0.026)\end{array}$ & $\begin{array}{l}-0.005 \\
(0.027)\end{array}$ \\
\hline Year Fixed Effects & No & No & Yes \\
\hline Firm and Institution Fixed Effects & Yes & Yes & Yes \\
\hline Phase Fixed Effects & Yes & Yes & Yes \\
\hline Indication Fixed Effects & Yes & Yes & Yes \\
\hline Observations & 23,159 & 23,159 & 23,159 \\
\hline$R$-squared & 0.120 & 0.129 & 0.154 \\
\hline Adjusted $R$-squared & 0.068 & 0.077 & 0.103 \\
\hline
\end{tabular}


Table A.7. Public Status, Multiple Projects, and Effects of the FDAAA on Project Suspension

The table presents results from the tests that examine the effects of public status on suspension decisions after the FDAAA. The sample consists of 16,916 project-year observations from the BioMedTracker database for the sample period from 2002 to 2012. The dependent variable is Suspension (Indicator) that is one if the project is suspended in a given year or has no progress update for the duration longer than the 90th percentile of the sample duration with the same phase and zero otherwise. Post (Indicator) is one for project-years in the post-FDAAA period and zero for the pre-FDAAA period. We consider samples of projects that are sponsored by publicly-listed companies in Columns 1 and 2 and by private companies in Columns 3 to 4 . We divide each sample into two groups of firms with multiple projects and a single project. The detailed descriptions of other variables are available in Appendix D. Standard errors reported in parentheses are robust and clustered by industry. $* * *, * *$, and * indicate statistical significance at the $1 \%, 5 \%$ and $10 \%$ levels, respectively.

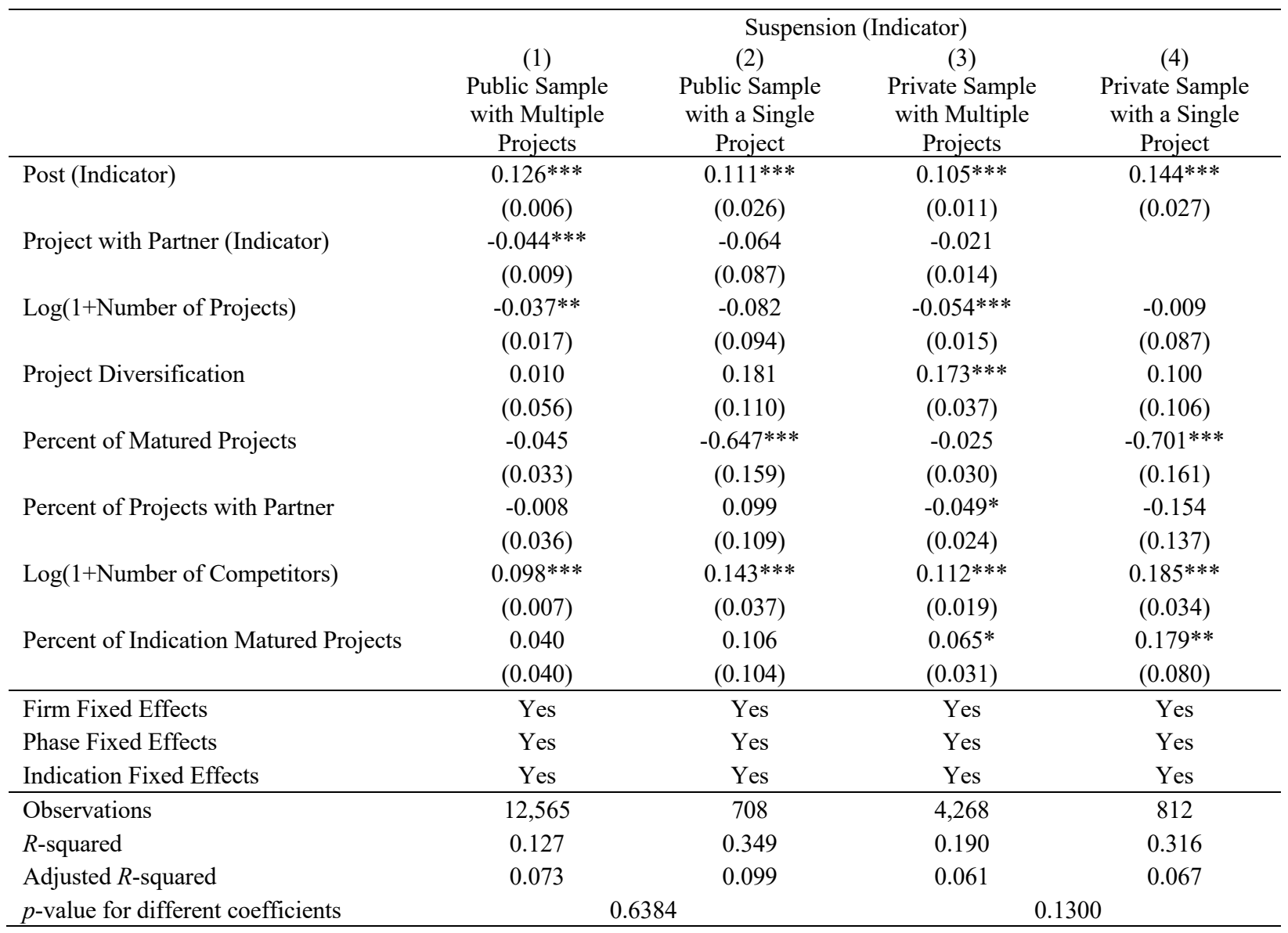

